\title{
Long-term monitoring for the condition-based structural maintenance of the Milan Cathedral
}

\author{
Carmelo Gentile $^{\mathrm{a}, *}$, Antonello Ruccolo ${ }^{\mathrm{b}}$, Francesco Canali ${ }^{\mathrm{c}}$ \\ a Politecrico di Milano, Department of Architecture, Built Environment and Construction Engineering (ABC), Piazza Leonardo da Vinci, 32,20133 Milan, Italy \\ 'Politecrnico di Milano, Piazza Leonardo da Vind, 32, 20133 Milan Italy \\ 'Veneranda Fabbrica del Duomo di Milano, Via Carlo Maria Martini, 1, 20122 Milan, Italy
}

\section{H I G H L I G H T S}

- The largest monitoring system ever installed in a historic monument is described.

- Selected results of both static and dynamic monitoring are presented.

- Temperature is a dominant driver of the structural parameters variation.

- The natural frequencies are affected by temperature in a distinctive way.

- Mode shapes and mode complexity are approximately time invariant.

\section{A R T I C L E I N F O}

\section{Articie history:}

Received 30 June 2019

Received in revised form 25 September

2019

Accepted 26 September 2019

\section{Keywords:}

Cathedral of Milan

Condition-based maintenance

Continuous monitoring

Mode shapes

Natural frequencies

Temperature

\begin{abstract}
A B S T R A C T
The Milan Cathedral, whose main structures were erected between 1386 and 1813 , is one of the largest masonry monuments ever built. Within the traditional collaboration between Politecnico di Milano and Veneranda Fabbrica del Duomo di Milano-the historic Institution established in 1387 and responsible for the preservation and development of the Gathedral-a structural monitoring system was recently designed and implemented with the two-fold objective of assisting the condition-based structural maintenance of the Cathedral and creating a large archive of experimental data, useful to improve the knowledge of the monument.

The new monitoring system, fully computer based and with efficient transmission of the collected data, includes static and dynamic measurements. The static monitoring system consists of: (a) bi-axial tiltmeters installed at the top of selected piers and at 3 levels of the Main Spire; (b) vibrating wire extensometers mounted on the iron tie-rods which are characterized by the higher tensile stress: (c) temperature and humidity sensors for the measurement of internal and external environmental parameters. The dynamic monitoring is performed through seismometers (electro-dynamic velocity sensors) installed at the top of 14 selected piers and at 3 levels of the Main Spire.

After a concise historic background on the Milan Gathedral and the description of the sensing devices installed in the church, the paper focuses on the results obtained during the first months of monitoring (since October 16th, 2018) and the lessons learned in view of the Structural Health Monitoring (SHM) of the monument.
\end{abstract}

2019 Elsevier Ltd. All rights reserved. 


\title{
LONG-TERM MONITORING FOR THE CONDITION-BASED STRUCTURAL MAINTENANCE OF THE MILAN CATHEDRAL
}

\author{
Carmelo Gentile $^{1}$, Antonello Ruccolo ${ }^{2}$, Francesco Canali ${ }^{3}$ \\ ${ }^{1}$ Politecnico di Milano, Milan, Italy \\ Department of Architecture, Built environment and Construction engineering ( $A B C)$ \\ Piazza Leonardo da Vinci, 32 - 20133 Milan, Italy \\ Phone: +39 022399 4242; Fax: +3902 23994220 \\ e-mail: carmelo.gentile@polimi.it \\ ${ }^{2}$ PhD Candidate, Politecnico di Milano, Milan, Italy \\ Piazza Leonardo da Vinci, 32 - 20133 Milan, Italy \\ ${ }^{3}$ Chief Technical Officer \\ Veneranda Fabbrica del Duomo di Milano \\ Via Carlo Maria Martini, 1 - 20122, Milan, Italy
}

\begin{abstract}
The Milan Cathedral, whose main structures were erected between 1386 and 1813, is one of the largest masonry monuments ever built. Within the traditional collaboration between Politecnico di Milano and Veneranda Fabbrica del Duomo di Milano - the historic Institution established in 1387 and responsible for the preservation and development of the Cathedral - a structural monitoring system was recently designed and implemented with the two-fold objective of assisting the condition-based structural maintenance of the Cathedral and creating a large archive of experimental data, useful to improve the knowledge of the monument.

The new monitoring system, fully computer based and with efficient transmission of the collected data, includes static and dynamic measurements. The static monitoring system consists of: (a) bi-axial tilt-meters installed at the top of selected piers and at 3 levels of the Main Spire; (b) vibrating wire extensometers mounted on the iron tie-rods which are characterized by the higher tensile stress; (c) temperature and humidity sensors for the measurement of internal and external environmental parameters. The dynamic monitoring is performed through seismometers (electro-dynamic velocity sensors) installed at the top of 14 selected piers and at 3 levels of the Main Spire.

After a concise historic background on the Milan Cathedral and the description of the sensing devices installed in the church, the paper focuses on the results obtained during the first months of monitoring (since October 16th, 2018) and the lessons learned in view of the Structural Health Monitoring (SHM) of the monument.
\end{abstract}

Keywords: Cathedral of Milan, Condition-based maintenance, Continuous monitoring, Mode shapes, Natural frequencies, Temperature 


\section{HIGHLIGHTS}

- The largest monitoring system ever installed in a historic monument is described

- Selected results of both static and dynamic monitoring are presented

- Temperature is a dominant driver of the structural parameters variation

- The natural frequencies are affected by temperature in a distinctive way

- Mode shapes and mode complexity are approximately time invariant 


\section{INTRODUCTION}

The Institution named Veneranda Fabbrica del Duomo di Milano [1], denoted as Fabbrica in the following, was established in 1387 to manage all operational aspects related to the construction, maintenance and restoration of the Milan Cathedral [2]. After the completion of the church structures, the Fabbrica main mission moved from construction to maintenance, implying continuous inspection and architectural restoration of surfaces, decorations and statues in Candoglia marble. Furthermore, remarkable structural interventions are reported in the recent history of the Milan Cathedral, especially on the Main Spire [3-5] and the piers supporting the dome and the tiburio [6] (i.e., the prismatic structure with octagonal base, which is built around the dome). Consequently, the preservation of the church has been traditionally assisted by the installation of different sensing devices, aimed at investigating specific issues. For example, an innovative inverted pendulum [7] was installed on late September 1904 in the Main Spire to measure the deformations induced by strong winds; more recently, taking profit of the architectural restoration preceding EXPO 2015, all the metallic tie-rods of the Cathedral were directly inspected and subjected to dynamic tests [8].

During the assessment of the tie-rods and taking profit of a joint research project between the Fabbrica and Politecnico di Milano, the idea to perform condition-based structural maintenance has been taking shape and a monitoring system was designed [9], with the objectives of providing the information needed for the condition-based structural maintenance and the creation of a large archive of experimental data useful to improve the knowledge of the monument. The study of several historic documents, as well as the analysis of more recent information, allowed to identify the sub-structures to be specifically considered in the start-up phase of the continuous monitoring: (a) the Main Spire [2-4]; (b) selected piers, which are placed in key areas of the church (i.e., apse, tiburio, transepts, main naves and façade); (c) the tie-rods subjected to high tensile stress or affected by slight damage [8].

Different sensing technologies were adopted in order to allow appropriate tracking of different long-term structural behaviour. The dynamic monitoring of the horizontal response of the piers and along the Main Spire is complemented by the measurement of the quasi-static 
tilt of the same sub-structures, whereas the static monitoring of strain in the tie-rods gives a direct evaluation of the structural condition of those elements (as the tensile force and stress in the tension bars is known [8]).

Since both the long-term static behaviour and the time evolution of dynamic signatures are expected to be sensitive also to factors other than structural changes [10] and especially the temperature might affect the variation of structural parameters in historic masonry structures (see e.g. [11-18]), the indoor and outdoor environmental parameters (temperature and relative humidity) are extensively measured with the two-fold objective of establishing correlations with the structural parameters changes [11-18] and evaluating the risks for the preservation of the many artifacts present in the Cathedral [19].

Due to the dimensions of the Cathedral and the relatively large number of sensors (more than 120) to be installed, a distributed sensor network was implemented to minimize wiring inside the building, with the network allowing on-site data acquisition and real-time data transfer to remote site. In short, the distributed sensor network includes: (a) 15 bi-axial tilt-meters (12 on the capital of selected piers and 3 in the Main Spire), each with integrated temperature sensors; (b) 12 extensometers on selected tie-rods; (c) 12 hygrometers inside the church; (d) one weather station at the top of the Main Spire and (e) 36 seismometers (27 inside the Cathedral and 9 in the Main Spire).

It is worth noting that the monitoring system of the Milan Cathedral is - to the authors' knowledge - the largest ever installed in a Cultural Heritage monument and is the first truly aimed at assisting the condition-based structural maintenance. Previous implementations in historic monuments reported in the literature [11-18] involved the use of a limited number of sensing devices and were aimed at effectively addressing specific issues (such as controlling the structural effects of restoration processes [14] or monitoring the dynamic characteristics of historic buildings in seismic areas [12], [15-16]).

When a few accelerometers or seismometers are installed in the structure, resonant frequencies are often assumed as representative of the structural condition so that the 
detection of anomalies should include the removal of the temperature effects on identified frequencies [11-18]. In the case of Milan Cathedral, the dynamic response of the structure is continuously collected in a reasonably well distributed measurement grid (27 channels of data), so that mode shapes-based methods (see e.g. [20]) could be conveniently used for damage detection and localization. Those methods conceivably exhibit advantages because mode shapes contain also local information on the structural behaviour and might be less sensitive than resonant frequencies to exogenous factors [20-22].

The present paper is mainly aimed at presenting selected results from the long-term monitoring of the Milan Cathedral. After a concise historic background of the historic monument (Section 2), full details are given on the sensing devices [23-24] and the software tools that are employed to perform the on-line processing of the continuously acquired data (Section 3). Subsequently, the dynamic characteristics of the Cathedral, that were identified in the first hours of dynamic monitoring, are presented and discussed (Section 4). The last part of the paper (Section 5) focuses on the results of the continuous (static and dynamic) monitoring for a period of 6 months and special attention is paid to the influence of environmental parameters on the variations observed in the quasi-static measurements (strain of the tie-rods and tilt of the piers) as well as in the resonant frequencies. Furthermore, clear evidence of the time-invariance of mode shapes and mode complexity [25-27] is highlighted, within a perspective of Structural Health Monitoring (SHM) and condition-based structural maintenance [21].

\section{DESCRIPTION OF THE CATHEDRAL AND HISTORIC BACKGROUND}

The Milan Cathedral (Figs. 1-3), erected between 1386 and 1813, is the most representative landmark of the city of Milan and one of the largest masonry monuments ever built. The church exhibits a unique style of architecture, which is characterized by a fusion of European Gothic style and Lombardy tradition, with the presence of neo-classic, neo-gothic and even renaissance influences due to the long period required by the construction works. 
(a)

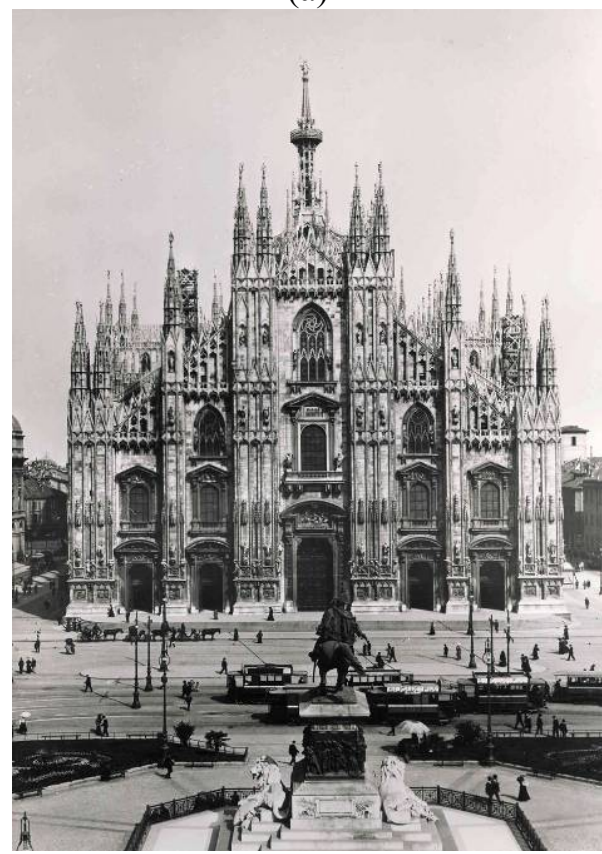

(b)

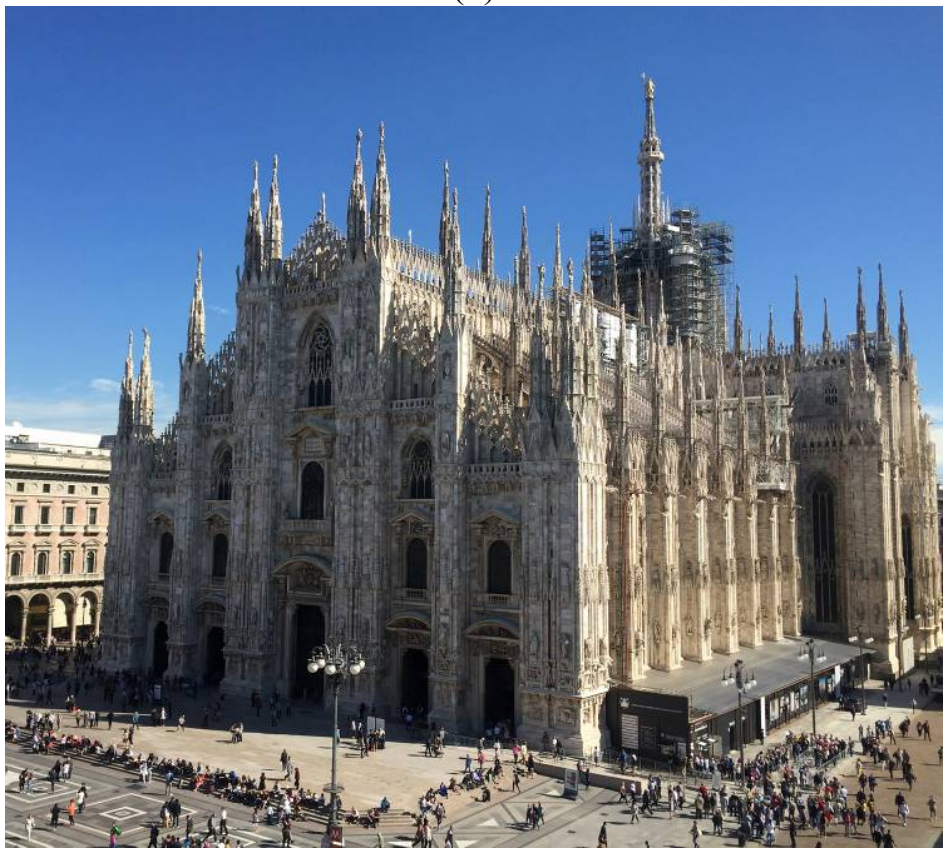

Fig. 1. Views of the Milan Cathedral (courtesy of Veneranda Fabbrica del Duomo di Milano).

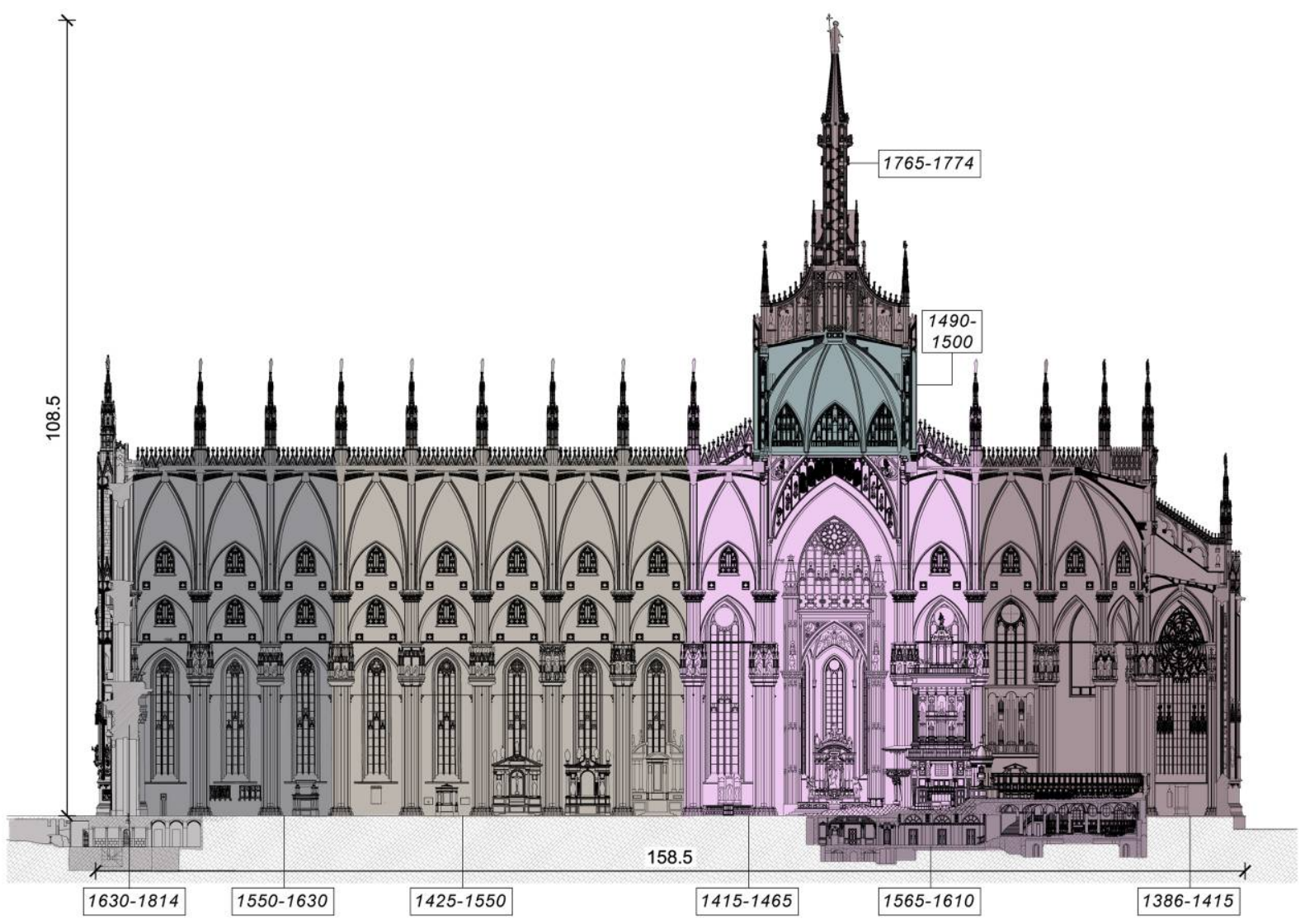

Fig. 2. Longitudinal section of the Milan Cathedral (dimensions in $\mathrm{m}$ ) and chronology of the main construction phases (courtesy of Veneranda Fabbrica del Duomo di Milano). 
(a)

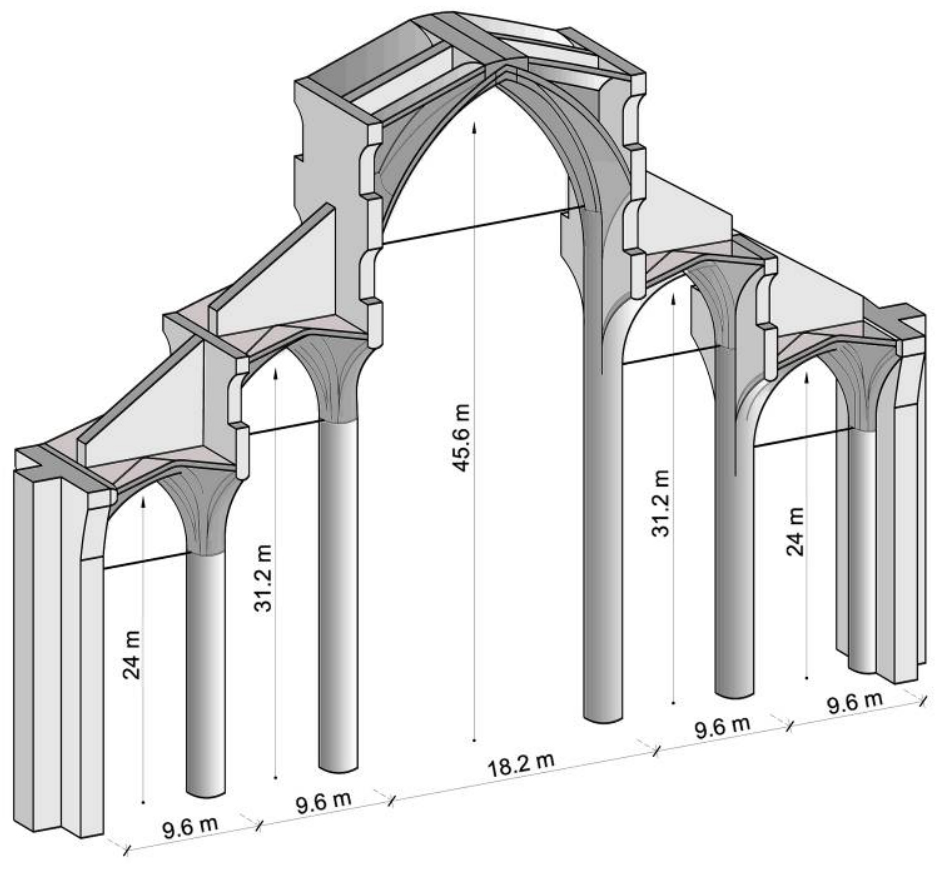

(b)

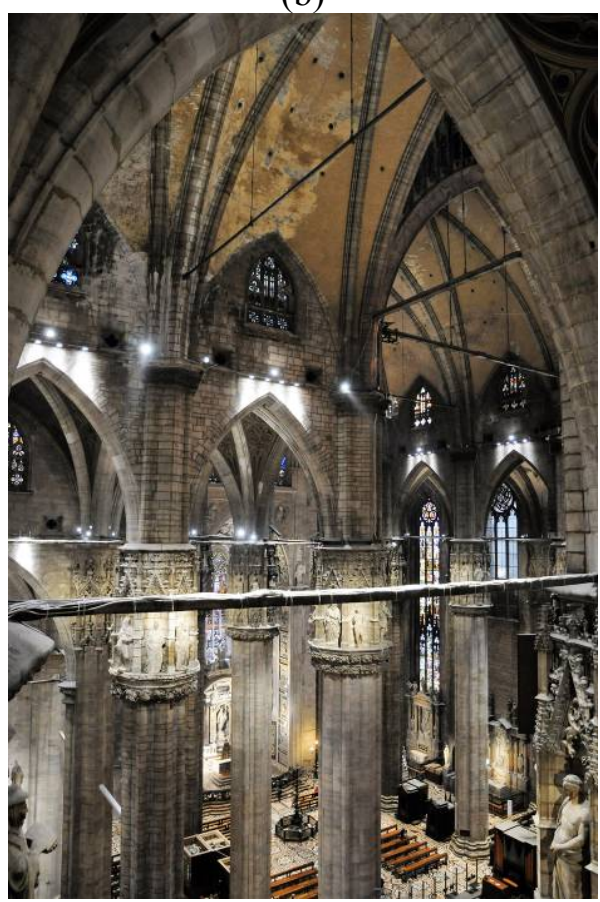

Fig. 3. (a) Schematic of the structural arrangement exemplified on one bay of the Milan Cathedral; (b) Inside view of arches, vaults and iron tie-rods.

An essential chronology of the construction phases is summarized in Fig. 2 with reference to the longitudinal section of the Cathedral. It is further noticed that the last gate of the church was inaugurated on January 6th, 1965 and this is usually considered to be the end of monument construction. The Milan Cathedral is characterized by a cross-shaped plan (Figs. 4a and 5), where the longitudinal limb (E-W) exhibits a central nave and two couples of side aisles (Fig. 3), and ends into an apse. The transept, about $49 \mathrm{~m}$ long (E-W) and $86 \mathrm{~m}$ wide (NS), intersects the longitudinal limb and has a main nave and two side aisles. The crossing between main nave and transept is capped with a main dome, supporting the Main Spire and surrounded by an octagonal tiburio. The main altar is placed below the tiburio and is surrounded by a semicircular choir and the polygonal de-ambulatory. The overall dimensions of the Latin cross-shaped plan are about $66 \mathrm{~m} \times 158 \mathrm{~m}$ (Figs. 4a and 5), with the central nave and the side aisles spanning $18.2 \mathrm{~m}$ and $9.6 \mathrm{~m}$, respectively (Fig. 3).

The building spreads over an area of more than $10400 \mathrm{~m}^{2}$, with a volume of about $300000 \mathrm{~m}^{3}$, so that it is the second largest Gothic cathedral in the world by volume and area. Moreover, the church exhibits the second tallest main nave among Gothic cathedrals, with the height of 
the vault intrados of the main nave being at about $45 \mathrm{~m}$ from the ground (Fig. 3). The perimeter load-bearing walls are built in dry masonry of varying thickness, with coatings in pink-veined white marble from the Candoglia quarries. Moreover, all the spires and the statues (about 3400) adorning the Cathedral are made in Candoglia marble.

The structural arrangement of the main limb is exemplified in Fig. 3a, highlighting the presence of double masonry vaults (i.e., cross vaults and barrel vaults) and of permanent metallic tie-rods placed under each arch (Fig. 3b). The vaults exhibit decreasing heights from 45.6 (vault intrados of the main nave) to $24.0 \mathrm{~m}$ (vault intrados of the side aisle) according to a specific proportion worked out by mathematician Gabriele Stornaloco in late 14th century [2], [28]. It is worthy mentioned that the adoption of iron tie-rods is unique in Gothic cathedrals, where wooden or metallic ties were used as provisional elements and removed at the end of the construction: on the contrary, the tension bars of the Milan Cathedral were designed to reduce the horizontal thrust on the slender lateral buttresses [2] and are still active in resisting the thrusts [8]. A total of 122 metallic tie-rods (Figs. 3a and 3b) is nowadays present in the Milan Cathedral and most of them are the original elements dating back to the age of construction.

Figure $3 \mathrm{a}$ also highlights that the double system of overlapping masonry vaults provides the support for the roof of main nave, giving rise to accessible spaces and walkways called "sordis": those spaces are connected with the interior of the church through holes in the vault system and windows and provide a good solution for installing the data acquisition devices of monitoring systems.

\section{THE MONITORING SYSTEMS}

Based on knowledge of the Cathedral and in order to characterize the current health state of the monument and to address its condition-based structural maintenance, the following key parameters are continuously measured or identified from the measurements: (a) tilt of selected piers and Main Spire; (b) strain in a certain number of tie-rods; (c) environmental parameters; (d) dynamic characteristics (i.e., resonant frequencies, associated modal deflections and 
damping ratios). Due to the different technical characteristics of the various sensing devices and sampling rates of the data acquisition, two separated long-term monitoring systems - one static and the other dynamic - were installed in the church. Strains, rotations and environmental data were collected at a rate of two samples per hour, whereas sampling frequency of $100 \mathrm{~Hz}$ was adopted in the dynamic monitoring. It is further noticed that the

monitoring systems are fully computer based and their architecture has been established in order to minimize wiring, as well as the visual impact of the sensing devices inside the Cathedral.

\subsection{Static monitoring system}

The static monitoring system includes the following sensors:

- 12 bi-axial tilt meters (Figs. $4 \mathrm{a}$ and $4 \mathrm{~b}$ ), with measurement range of $\pm 0.5^{\circ}$ and resolution of $\pm 0.5 \mathrm{~mm} / \mathrm{m}$, are installed inside the church. As shown in Fig. $4 \mathrm{~b}$, those tilt meters are mounted on the capital of pier 31 and 64 (façade), 69 and 90, 11 and 20 (transept), 74-75 and 84-85 (tiburio) and 47-48 (apse). It should be noted that temperature sensors, with measurement range varying between $-20^{\circ} \mathrm{C}$ and $+60^{\circ} \mathrm{C}$ and resolution of $0.2^{\circ} \mathrm{C}$, are integrated with each tilt meter [23]. The temperature sensors allow the compensation of the temperature effect on the measurement of each (individually calibrated) tilt meter and, at the same time, measure the (indoor or outdoor) air temperature;

- 3 bi-axial tilt meters (with integrated temperature sensors) [23], installed at different levels (+65.87 m, $74.99 \mathrm{~m}$ and $+91.67 \mathrm{~m}$ with respect to the ground) of the Main Spire;

- 12 vibrating wire extensometers (Figs. $4 \mathrm{a}$ and $4 \mathrm{c}$ ), with measurement range of $\pm 3000 \mu \varepsilon$ and resolution of $1 \mu \varepsilon$. The extensometers are installed on 10 iron ties (highlighted in red in Fig. 4a) subjected to tensile stress larger than $100 \mathrm{MPa}$ and on tie-rods 38-72 and 57-87, affected by slight damage [8];

- 12 hygrometers, with measurement range $0-100 \%$ and resolution of $1 \%$, mounted in the neighbourhood of the extensometers;

- One weather station installed on the higher accessible level of the Main Spire (+91.67 m). Although the position of the weather station is not optimal for the evaluation of wind 
parameters, its choice was motivated by the possibility of carrying out an easy maintenance of the device. Unlike the other static measurements, the data from the weather station are collected every 5 minutes.

(a)

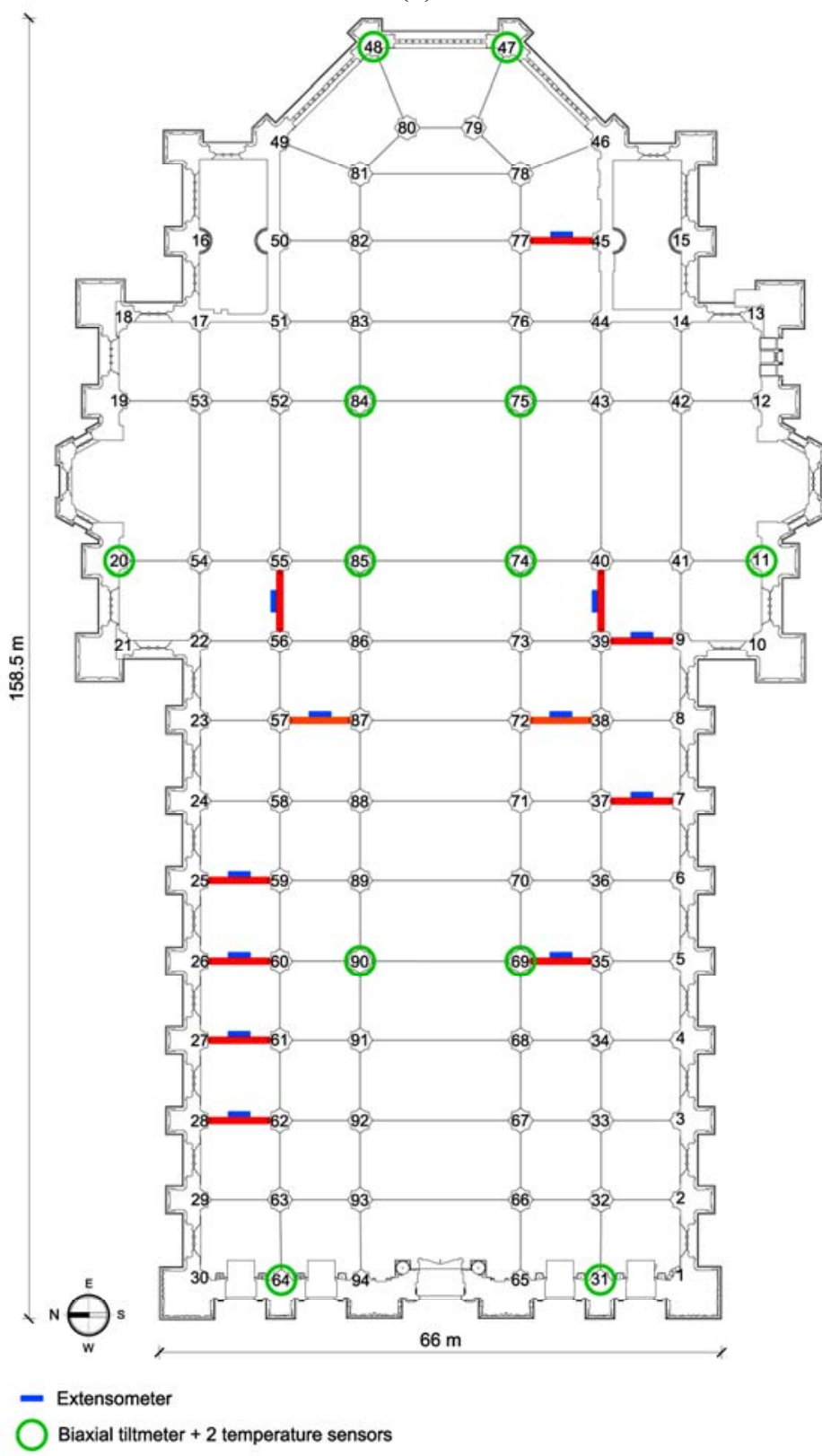

(b)

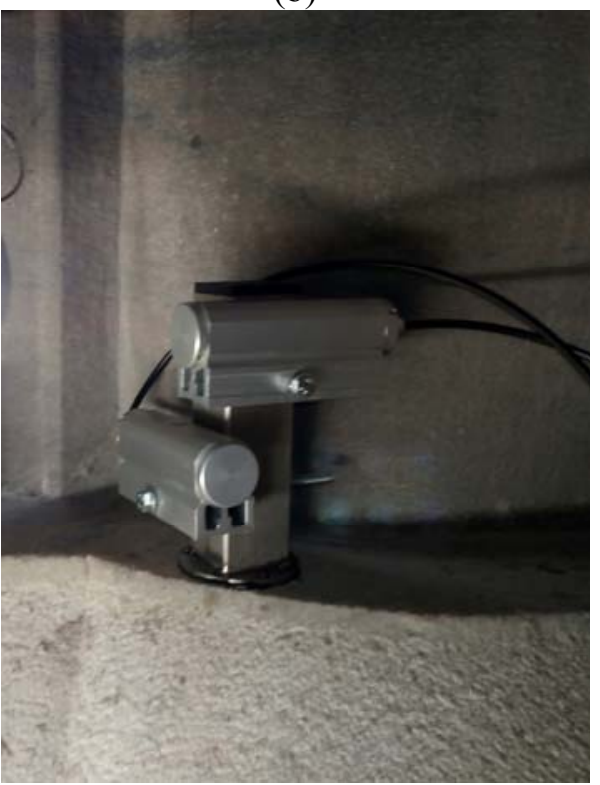

(c)

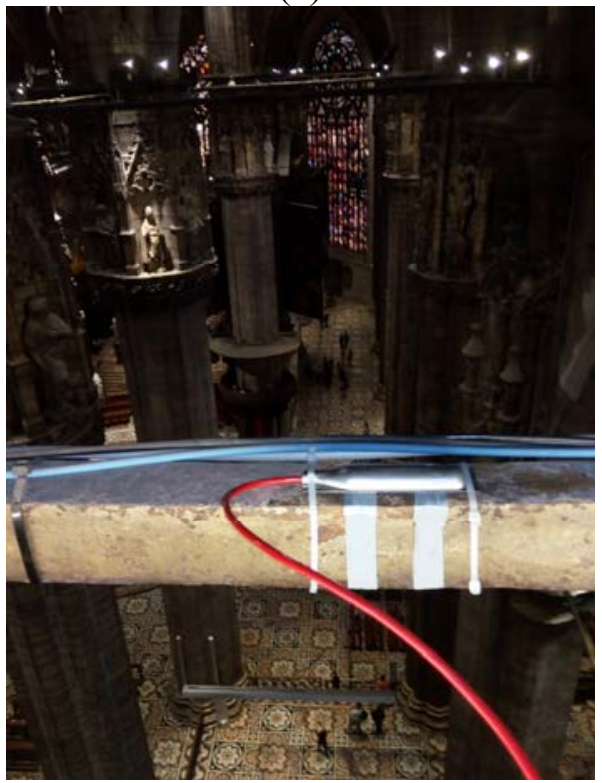

Fig. 4. (a) General layout of the static monitoring system installed in the Cathedral (dimensions in $\mathrm{m}$ ); (b) Bi-axial tilt meter mounted on one capital; (c) Extensometer installed on one tie-rod.

The data transfer from the static monitoring devices inside the Cathedral is wireless but each sensor is wired to high capacity batteries, which are placed in the "sordis" walkways over the vaults, quite easy to access for maintenance and substitution. At the sampling rate of two per 
hour, the expected power charge should be around 3 years.

The measured data are collected by a local workstation managed by the Fabbrica technical staff. The local workstation is equipped with appropriate software codes aimed at the remote management and check of the different devices; in addition, through the internet, the data are processed by authorized users (such as Politecnico di Milano) and the compressed results are send back to Fabbrica workstation for direct check and decision making as well as for being stored in digital archives. It should be mentioned that similar system architecture and procedures are adopted for the dynamic monitoring, with the main difference that only the hourly evaluated features (i.e., the modal parameters) and a few time series corresponding to significant events) are permanently stored in the Fabbrica archives.

\subsection{Dynamic monitoring system}

The dynamic monitoring system is based on SARA SS45 seismometers (electro-dynamic velocity transducers) [24]. It should be noticed that high sensitivity $(78 \mathrm{~V} /[\mathrm{m} / \mathrm{s}])$, no need for powering and very good performance in the low frequency range $(f \leq 100 \mathrm{~Hz})$ makes the electro-dynamic transducers very attractive for the application in vibration testing or monitoring of civil engineering and cultural heritage [22] structures. In addition, it is well known from Earthquake Engineering and Seismology that retrieving the displacement time series from accelerometers is not an easy task: on the contrary, measuring the velocity time series through seismometers allows also to obtain estimates of the dynamic displacement by relatively simple integration. Needless to note that the displacement time series - especially of the slender Main Spire - will provide the Fabbrica with data generally not available and directly related to the stiffness and structural health.

The dynamic monitoring system consists of:

- 13 bi-axial seismometers and 1 mono-axial seismometer, installed at the top of selected piers inside the Cathedral (Fig. 5) and measuring the velocity in the two orthogonal N-S (transversal) and E-W (longitudinal) directions. The sensors (Fig. 6a) installed on piers $(94,92,90),(65,67,69),(22,85,84),(9,74,75)$ and $(47,48)$ are grouped and wired to 
five 24-bit digitizers SARA SL06 [24] (Fig. 6b); each digitizer is equipped with A/D conversion system, 8 GB memory, synchronization by GPS, back-up battery and UMTS modem for data transfer;

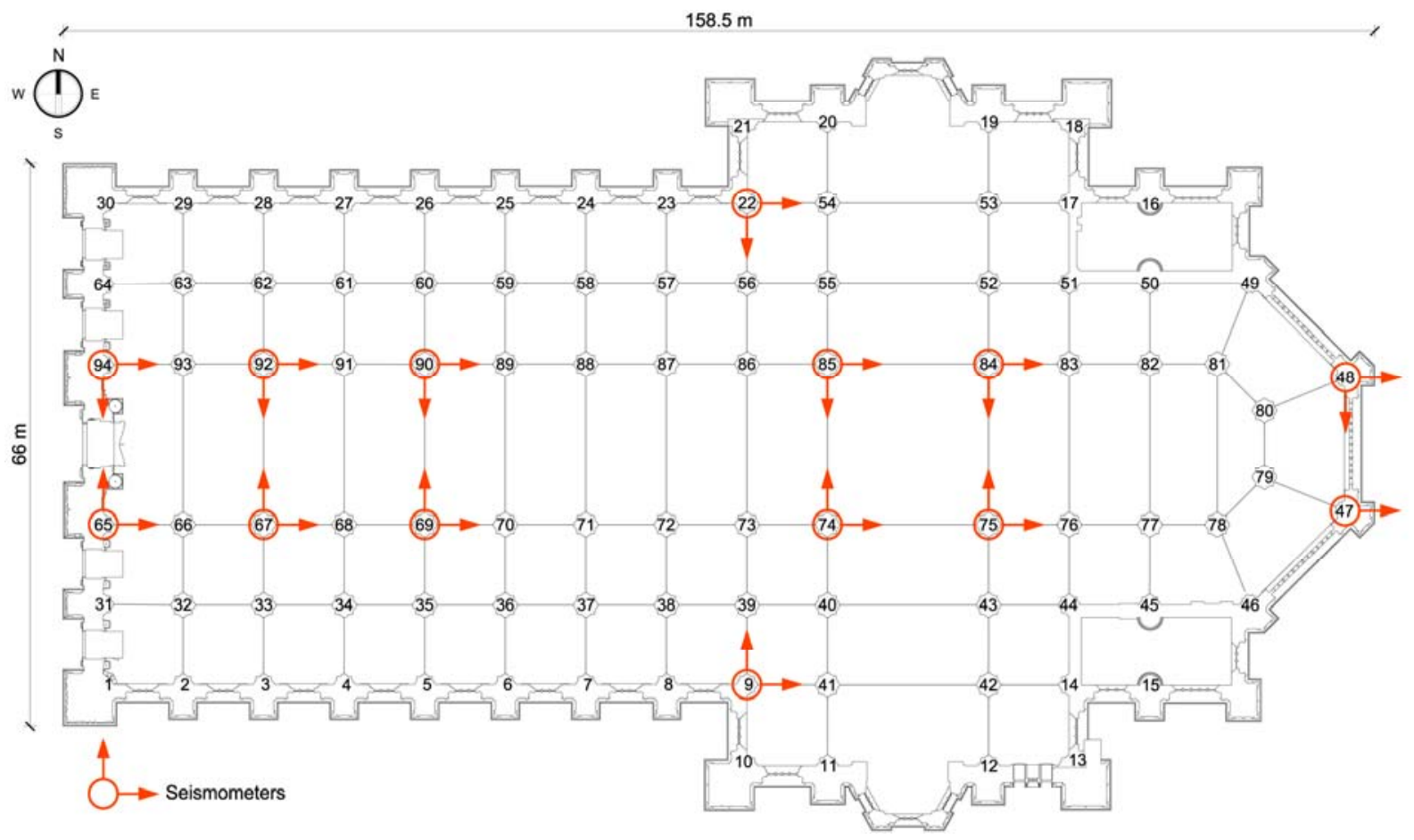

Fig. 5. General layout of the seismometers installed in the Cathedral (dimensions in $\mathrm{m}$ ).

(a)

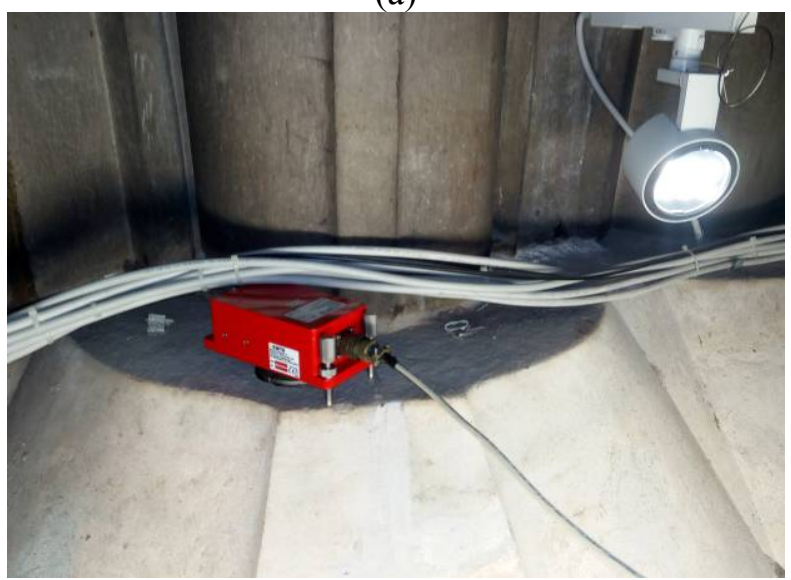

(b)

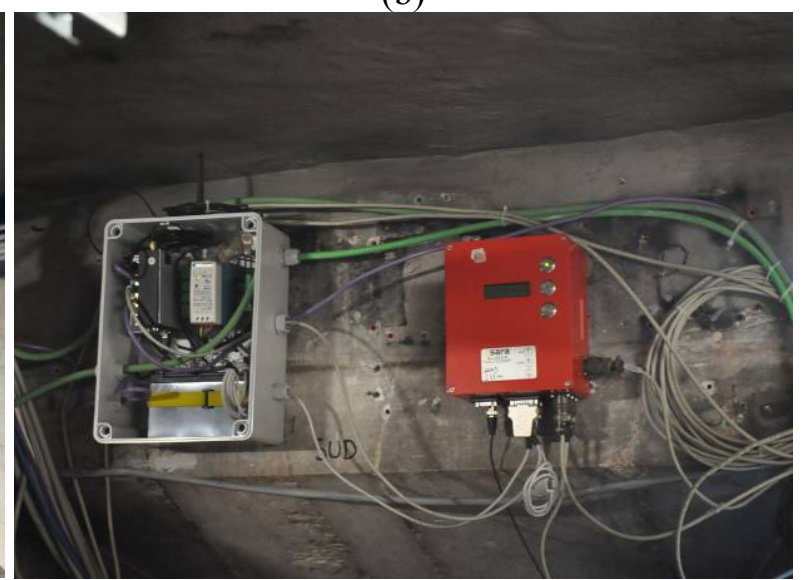

Fig. 6. (a) Seismometer and (b) digitizer installed in the Cathedral.

- $3 \times 3$ mono-axial seismometers, installed at the same levels of the main spire hosting the biaxial tilt-meters belonging to the static monitoring. The three sensors installed at each level are wired to 24-bit digitizer, with the digitizers being connected to a switch for data transfer. 
The velocity data are transferred in real time to the Fabbrica workstation and stored in separate files (compressed mini-seed format) of 1 hour. Every hour, the automatic signal processing involves the following tasks: (a) pre-processing the raw data (to compensate the low-frequency attenuation of the sensor) using the SEISMOWIN commercial software [24] and subsequent saving of the time series in text format; (b) data analysis to extract the maximum and the root mean square values and creation of a file in Matlab (.mat) format; (c) low-pass filtering and down-sampling (to reduce the sampling frequency from $100 \mathrm{~Hz}$ to 20 $\mathrm{Hz}$ ), and creation of a database of files (in binary or text format) for the application of the modal identification tools; (d) automated modal estimation and tracking.

\section{AUTOMATED IDENTIFICATION OF THE DYNAMIC CHARACTERISTICS OF THE MILAN CATHEDRAL}

\subsection{Automated modal identification}

The modal parameters of the Cathedral and of the Main Spire are independently identified using a fully automated procedure, based on the covariance-driven Stochastic Subspace Identification (SSI-Cov) algorithm [29] and developed in a previous study [30]. The length of the time window adopted in the automated identification was set equal to 1 hour $(3600 \mathrm{~s})$.

SSI procedures [29] are based on the discrete-time stochastic state-space form of the dynamics of a linear-time-invariant system under unknown excitation:

$$
\begin{aligned}
\boldsymbol{x}_{\mathrm{k}+1} & =\boldsymbol{A} \boldsymbol{x}_{\mathrm{k}}+\boldsymbol{w}_{\mathrm{k}} \\
\boldsymbol{y}_{\mathrm{k}} & =\boldsymbol{C} \boldsymbol{x}_{\mathrm{k}}+\boldsymbol{v}_{\mathrm{k}}
\end{aligned}
$$

where $k$ is the time step, $\boldsymbol{x}_{\mathrm{k}} \in \mathfrak{R}^{n}$ is the discrete-time state vector (containing displacements and velocities describing the state of the system at time $k$ ), $\boldsymbol{y}_{\mathrm{k}} \in \mathfrak{R}^{m}$ is the vector collecting the $m$ output measurements, $\boldsymbol{A} \in \mathfrak{R}^{n \times n}$ is the system matrix of order $n$ (containing the modal information of the structure), $C \in \mathfrak{R}^{m \times n}$ is the output matrix (mapping the state vector into the measured outputs), $\boldsymbol{w}_{\mathrm{k}}$ and is the process noise and $\boldsymbol{v}_{\mathrm{k}}$ is the measurement noise.

The SSI-Cov algorithm estimates the system matrix $\boldsymbol{A}$ by using the covariance matrix of the measured output vectors $\boldsymbol{y}_{\mathrm{k}}$. The adopted automated procedure [30] involves two main steps, 
i.e., modal parameter estimation (MPE) and modal tracking (MT):

(a) For each dataset, the MPE is performed through an automatic interpretation of stabilisation diagrams, based on the sensitivity of frequency and mode shape to the model order variation: the poles sharing similar frequencies and mode shapes are clustered together, and a set of representative modal parameters (i.e. resonant frequency, damping and mode shape) is estimated for each cluster. To increase the clustering efficiency, prior filtering of spurious poles is performed by checking the damping ratio and mode complexity value [25-27]. The mode complexity is checked by averaging the information provided by both the Modal Phase Collinearity [25] (MPC) and Mean Phase Deviation [25-26] (MPD) through the Modal Complexity Index $\left(\mathrm{MCI}=0.5 \times\left[(1-\mathrm{MPC})+\left(\mathrm{MPD} / 45^{\circ}\right)\right]\right.$, varying between 0 and 1, with 0 indicating a mono-phase behaviour of the identified mode shape) [30];

(b) The automated MT, aimed at providing the frequency evolution for each mode over the monitoring period, is based on frequency and MAC [31] variation with respect to a preselected list of baseline modes.

For the details on the automated modal identification, the interested reader is referred to [30]. As it is common to SSI-based approaches, the algorithm [30] needs some input parameters. In the application to the data collected on the piers of the church (Fig. 5), the following input parameters were assumed: (a) the time lag parameter $i$ needed to fill the $(m i \times m i)$ block Toeplitz covariance matrix [29] was set equal to 60; (b) the order of the model has been varied from 20 to 140; (c) in the noise modes filtering, the maximum allowable damping ratio and MCI [30] was set equal to $8 \%$ and 0.15 , respectively.

\subsection{Dynamic characteristics of the Milan Cathedral}

The grid of seismometers permanently installed in the Cathedral allowed the identification and fairly good spatial description of a relatively large number of key vibration modes. Typical results obtained in the first day of continuous monitoring, in terms of resonant frequencies and mode shapes, are shown in Figs. 7-8. 
Fig. 7 exemplifies the stabilization diagram obtained by applying the MPE algorithm [30] to the dataset (27 channels of data, Fig. 5) recorded on 17/10/2018 (h 12:00-13:00). The stabilization diagram in Fig 7 is shown after cleaning and selection (clustering) of physical modes, along with the first Singular Value (SV) line of the spectral matrix, which is the mode indication function adopted in the Frequency Domain Decomposition technique [32].

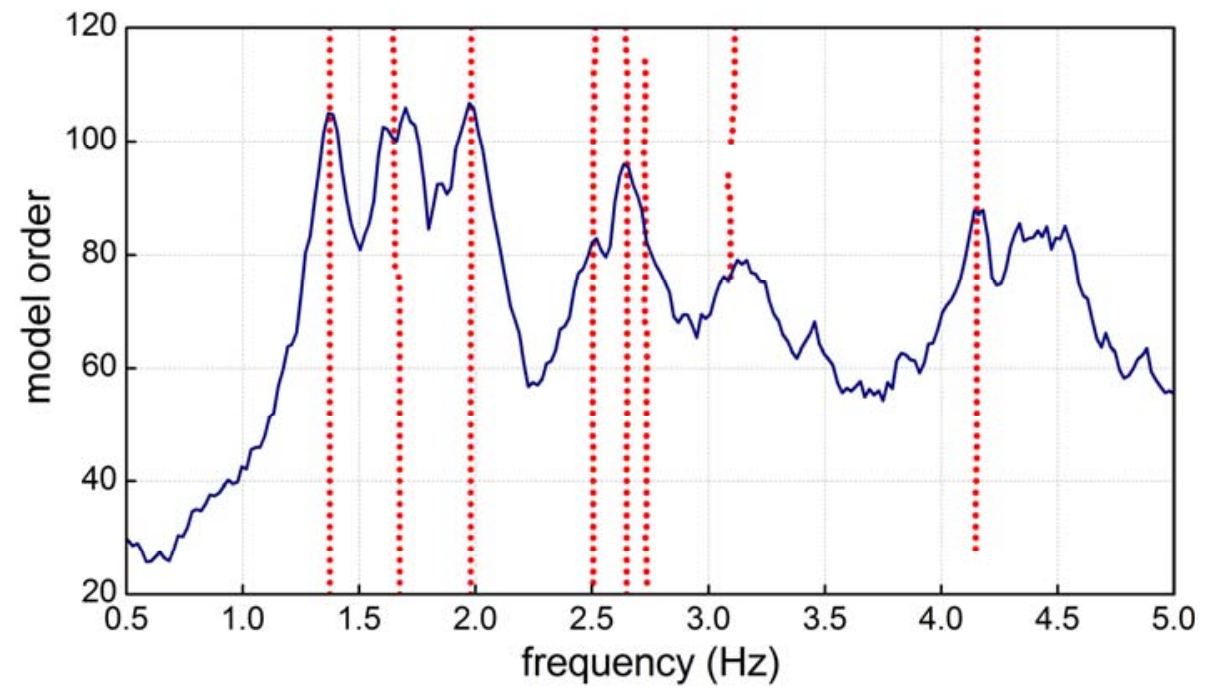

Fig. 7. Typical stabilization diagram obtained by applying the automated procedure [29] to signals collected in the Milan Cathedral (27 channels of velocity data, 17/10/2018, h 12:00-13:00).

The inspection of Fig. 7 highlights eight alignments of the stable poles, providing a clear indication of the structural modes and those alignments of poles generally correspond to local maxima in the first SV line. The corresponding mode shapes are shown in Fig. 8 (where the blue colour refers to modes with dominant motion in the N-S direction and the red colour refers to modes with dominant deflection in the E-W direction). The inspection of Fig. 8 allows the following comments:

(1) As it was already observed in preliminary tests [9] performed by installing accelerometers on the top of few piers, the lower two modes, denoted by $\mathrm{C} 1$ and $\mathrm{C} 2$, involve global sway deformation of all instrumented columns of the Cathedral in the N-S $\left(f_{\mathrm{C} 1}=1.38 \mathrm{~Hz}\right.$, Fig. 8b) and $\mathrm{E}-\mathrm{W}\left(f_{\mathrm{C} 2}=1.69 \mathrm{~Hz}\right.$, Fig. $\left.8 \mathrm{c}\right)$ direction, respectively;

(2) The subsequent modes $\mathrm{C} 3$ and $\mathrm{C} 4$, are characterized by dominant motion in the N-S direction and transverse bending of the naves. In more details, mode $\mathrm{C} 3\left(\mathrm{f}_{\mathrm{C} 3}=1.98 \mathrm{~Hz}\right.$, Fig. 8d) involves out-of-phase vibration of apse and façade, whereas mode $\mathrm{C} 4$ ( $\mathrm{f}_{\mathrm{C} 4}=1.98$ 
Hz, Fig. 8e) exhibits a deformed shape with 3 half-sine waves of the ideal E-W line connecting the capitals (i.e. two changes of sign from apse to façade);
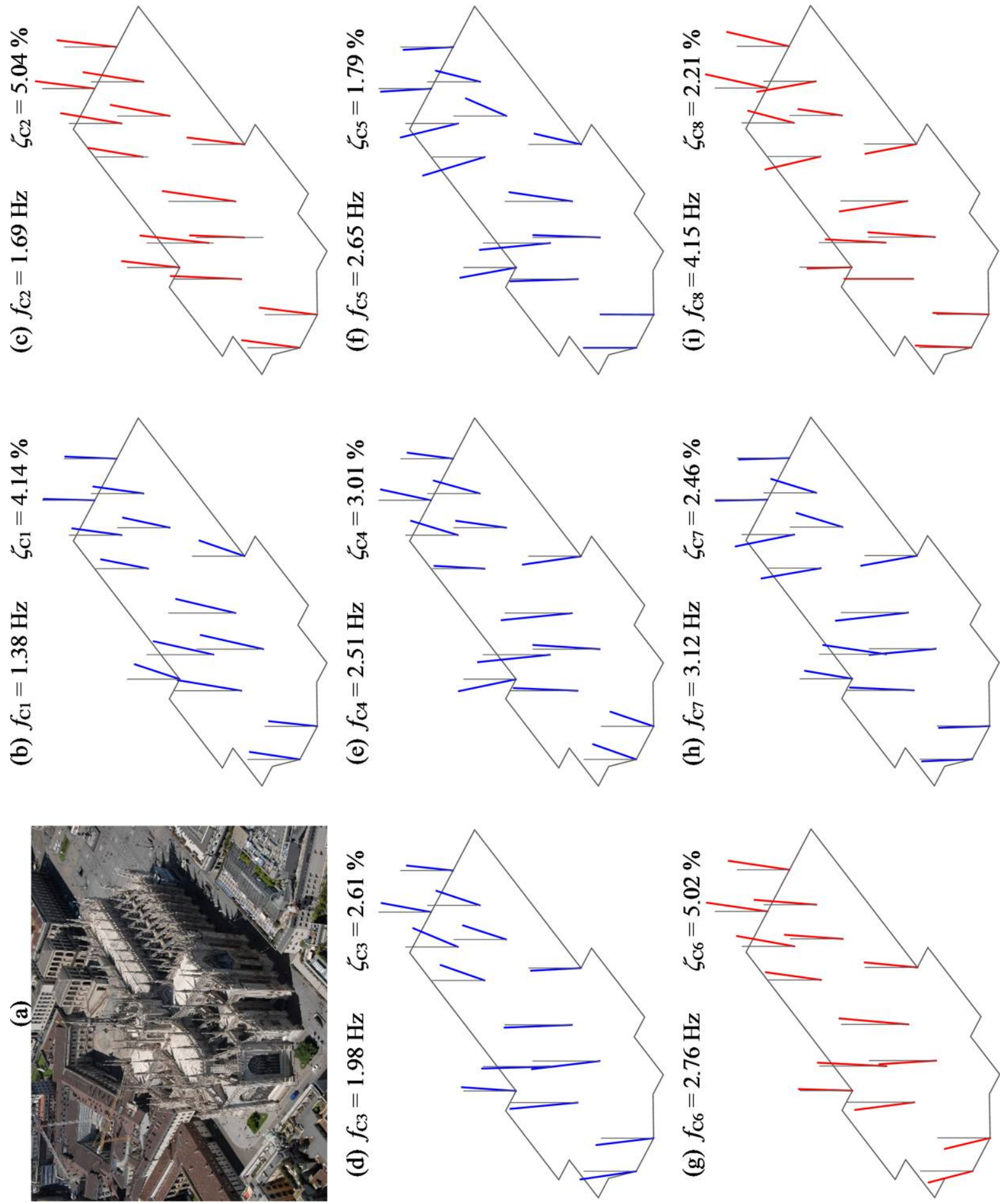

Fig. 8. (a) Aerial view of the Milan Cathedral from apse and (b)-(i) identified vibration modes (17/10/2019, h 12:00-13:00). 
(3) Modes C5 ( $f_{\mathrm{C} 5}=2.68 \mathrm{~Hz}$, Fig. 8f) and C7 ( $f_{\mathrm{C} 7}=3.12 \mathrm{~Hz}$, Fig. 8h) exhibit out-of-phase transverse $(\mathrm{N}-\mathrm{S})$ motion of the symmetric columns of each bay (with slight E-W motion of apse and façade);

(4) Mode C6 $\left(f_{\mathrm{C} 6}=2.76 \mathrm{~Hz}\right.$, Fig. $\left.8 \mathrm{~g}\right)$ is characterized by dominant displacement of all instrumented piers in the $\mathrm{E}-\mathrm{W}$ direction, with a phase change occurring in the area of tiburio;

(5) Mode $\mathrm{C} 8$ ( $f_{\mathrm{C} 8}=4.16 \mathrm{~Hz}$, Fig. 8i) has a distinctive shape, with dominant E-W deflection of the façade and N-S (out-of-phase) motion of the neighbouring inner piers;

(6) The N-S modes exhibit damping ratios varying from $1.79 \%(\mathrm{C} 5)$ to $4.14 \%(\mathrm{C} 1)$, whereas the damping of the E-W modes ranges between $2.21 \%(\mathrm{C} 8)$ and $5.04 \%(\mathrm{C} 2)$. It is further noticed that especially the damping ratio of longitudinal (E-W) modes seems to be larger than generally observed at the low level of ambient excitation existing on historical buildings.

As it will be discussed in Section 5, almost all modes identified in the first hours of continuous monitoring, have been automatically detected with high identification rate in the subsequent months.

\section{SELECTED RESULTS FROM THE CONTINUOUS MONITORING}

The dynamic and static monitoring is fully active since October 16th and October 19th 2019, respectively. This section summarizes selected results from the continuous monitoring over a time span of about six months (from 16/10/2018 to 13/04/2019) and, for the sake of consistency, only the experimental evidences on the Cathedral behavior are presented and discussed (with no comments being provided on the data collected on Main Spire).

As usual for masonry buildings [11-18, 22], the evolution in time of environmental parameters is firstly presented in order to understand the effects of changing environment on the variations observed in the quasi-static measurements (strain of the tie-rods and tilt of the piers) as well as in the resonant frequencies and mode shapes. 
(a)

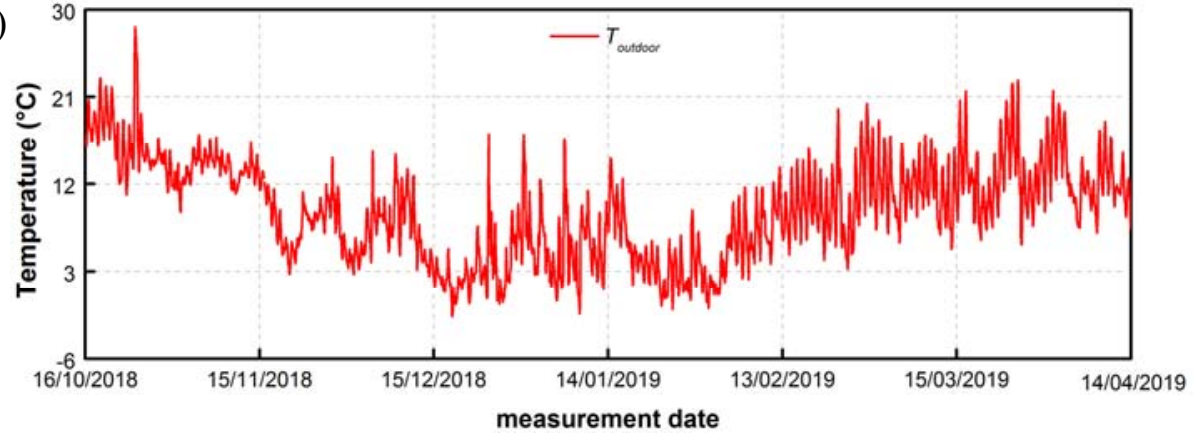

(b)

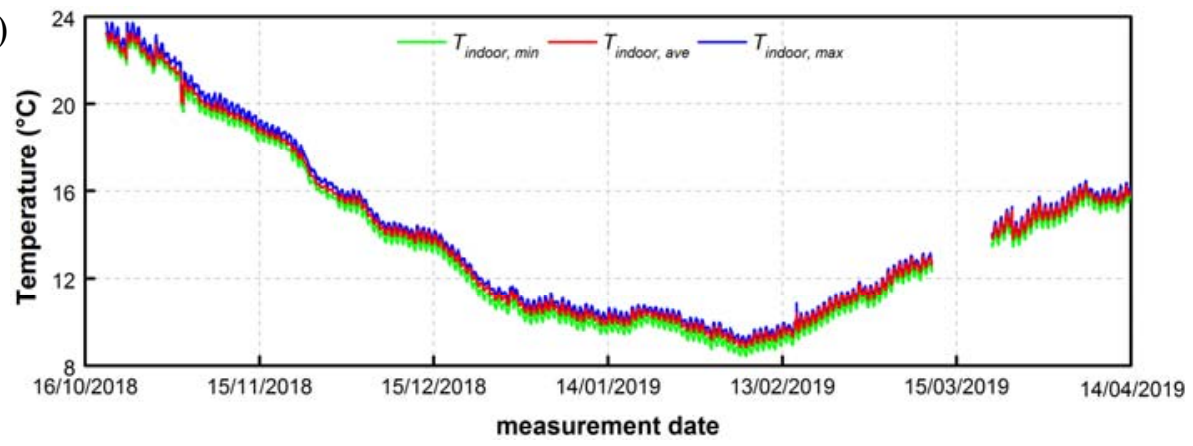

(c)

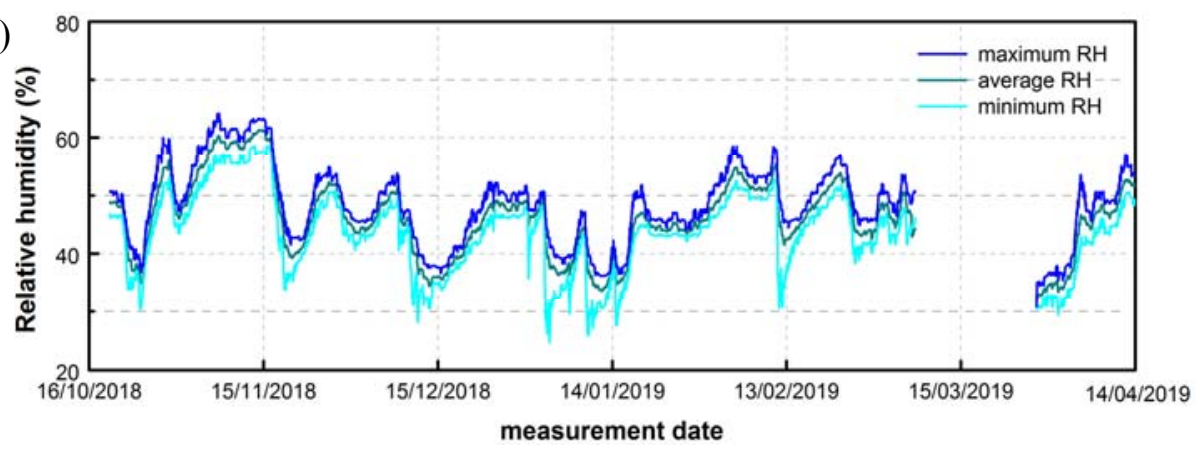

Fig. 9. Variation of the environmental parameters measured from 16/10/2018 to 13/04/2019:

(a) Outdoor temperature; (b) Temperature inside the Cathedral; (c) Humidity inside the Cathedral.

\subsection{Environmental parameters}

As previously pointed out, a quite extended grid of temperature sensors and hygrometers has been installed inside the church, with the objective of supporting both the SHM program and the preservation of statues, paintings and decorative elements, which are kept inside the monument. The variation in time of the outdoor and indoor temperature and indoor relative humidity is summarized in Fig. 9.

Fig. 9a presents the evolution of the outdoor temperature measured by the weather station and shows that the temperature changed between $-1.65^{\circ} \mathrm{C}$ and $+28.2^{\circ} \mathrm{C}$. The corresponding variations of indoor temperature are exemplified in Fig. $9 \mathrm{~b}$ through the minimum, average and maximum value. As expected from previous studies on the microclimatic condition in the 
Milan Cathedral [19], Fig. 9b highlights a very limited temperature gradient in space, with the range between the extreme values not exceeding $0.5^{\circ} \mathrm{C}$. Notwithstanding the large dimensions of the church, the low temperature gradient and the observed correlation between the measured temperatures, with the correlation coefficients being always larger than 0.99 , suggests to assume the average indoor temperature (Fig. 9b) as a representative quantity for the SHM correlations.

Fig. 9c presents the minimum and maximum value of the relative humidity measured inside the Milan Cathedral along with the average relative humidity: also the humidity time series are highly correlated, with the correlation coefficients being of the order of 0.90 or larger.

\subsection{Static behaviour and environmental effects}

As previously stated, the continuous monitoring is active from late October 2018 and the results collected in the first six months of monitoring are herein discussed. Since this period is too short for providing a comprehensive picture on the long-term static behaviour of the investigated structure, the effects exerted from environmental parameters on the measured strains and rotations are mainly investigated.

Fig. 10a exemplifies the variation in time of the strain measured on tie-rods $28-62$ and 39-09: it should be observed that, although those elements are located in the north and south side aisle of the limb (Fig. 4a), the strain trend is very similar. In addition, Figs. 10b and 10c reveals that the correlation between strain and indoor (average) temperature is very similar too, with the coefficient of determination $R^{2}$ being larger than 0.90 . Figs. $10 \mathrm{~b}$ and $10 \mathrm{c}$ also show slight deviations of the regression line from linearity. It is worthy mentioned that: (a) strain variation is also slightly affected from outer temperature (Fig. 9a), whereas negligible effects $\left(R^{2} \leq 0.095\right)$ are due to the (average) relative humidity; (b) trends and correlation values similar to the ones exemplified in Fig. 10 are found for all instrumented tie-rods, whose long-tem behaviour seems almost completely dominated by the indoor temperature.

The indoor temperature turns out to be the main driver of the changes observed in the piers rotation as well. Fig. 11a shows the evolution of the E-W rotation of selected piers: inspecting 
(a)

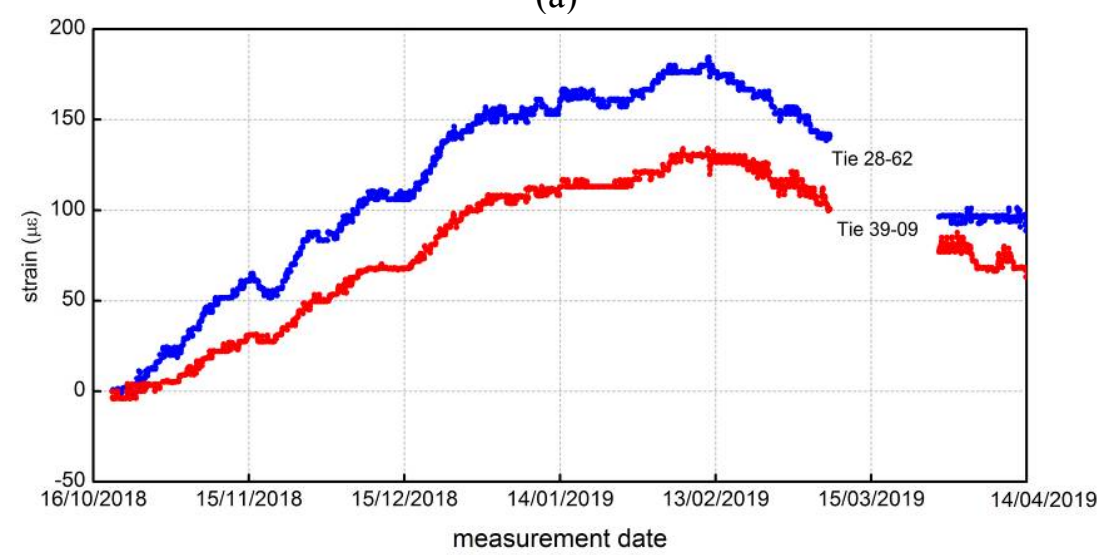

(b)

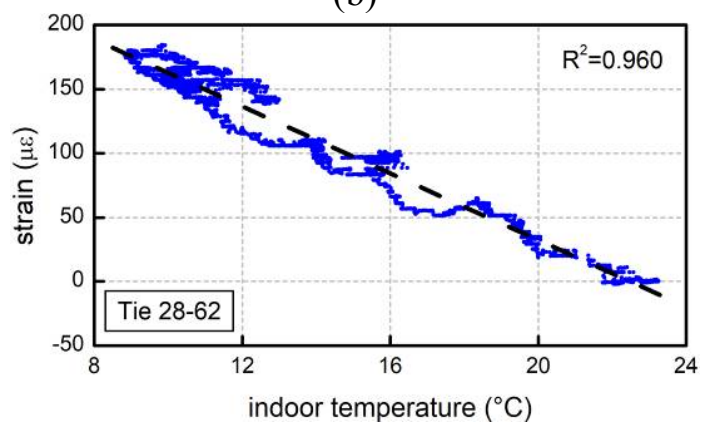

(c)

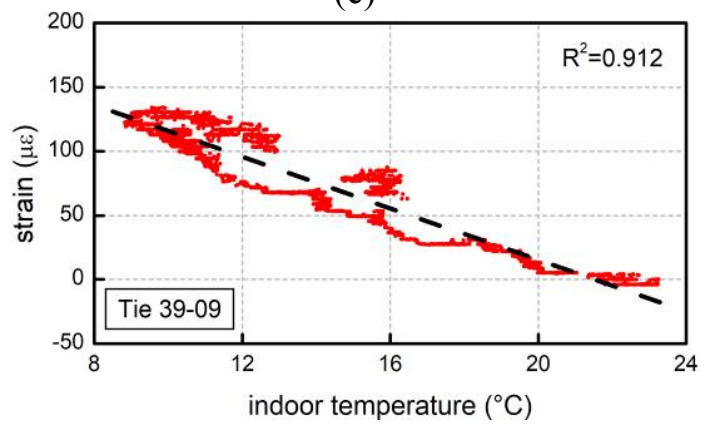

Fig. 10. (a) Strain variation in tie-rods $28-62$ and 39-09 from 16/10/2018 to 13/04/2019; (b) Straintemperature correlation for tie 28-62; (c) Strain-temperature correlation for tie 39-09.

(a)

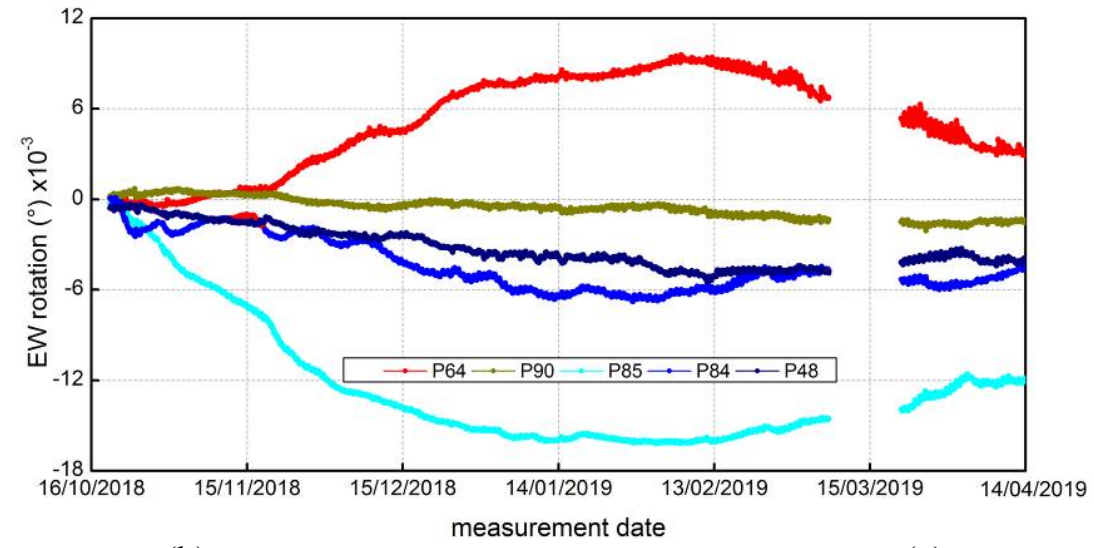

(b)

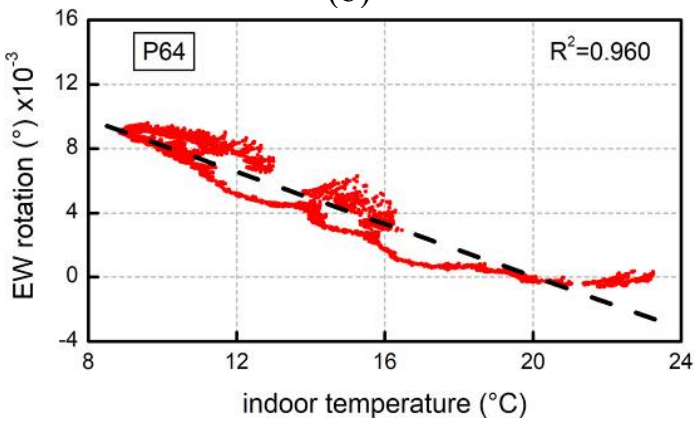

(c)

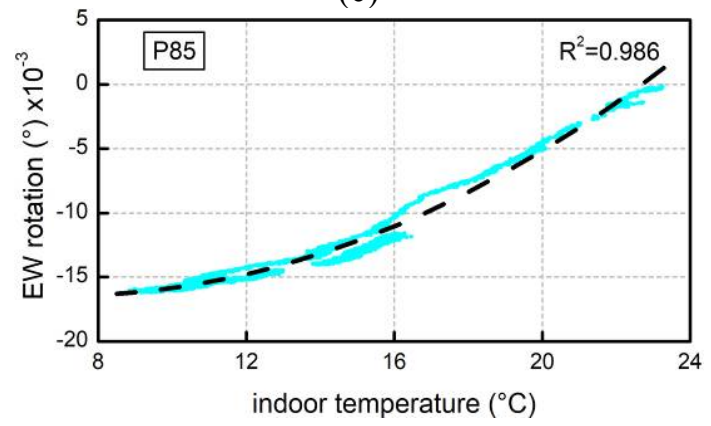

Fig. 11. (a) Variation of E-W rotation of selected piers from 16/10/2018 to $13 / 04 / 2019$; (b) Rotationtemperature correlation for pier 64 (façade); (c) Rotation-temperature correlation for pier 85 (tiburio). 
the tilt data shows that pier 64 (façade) tends to lean towards east (positive direction), whereas all other piers are leaning towards west, with pier 85 (tiburio) exhibiting the maximum tilt.

The correlation between E-W tilt and indoor (average) temperature for piers 64 and 85 is shown in Figs. 11b and 11c. As illustrated in Fig. 11c, a non-linear correlation between E-W rotation and indoor temperature is observed for pier 85. Moreover, the inspection of Figs. 9b, 11a and 11c suggests that the rotation of the same pier 85 , measured between the beginning of December 2018 and mid April 2019 (Fig. 11a) in the temperature range 9-16 ${ }^{\circ} \mathrm{C}$ (Fig. 9b), is almost completely recovered. In more details, the progressive rotation decrease observed as temperature decreases from $16^{\circ} \mathrm{C}$ to $9^{\circ} \mathrm{C}$ equals the rotation increase associated to the increase of temperature from $9^{\circ} \mathrm{C}$ to $16^{\circ} \mathrm{C}$ (Fig. 11c), with the two paths being almost superimposed.

\subsection{Dynamic characteristics and environmental effects}

Fig. 12 shows the time variation of the automatically identified resonant frequencies of the Milan Cathedral from 16/10/2018 to $13 / 04 / 2019$, whereas the statistics of natural frequencies and damping ratios are listed in Table 1. Table 1 summarizes the identification rate, the mean value $\left(f_{\text {ave }}\right)$ and the standard deviation $\left(\sigma_{\mathrm{f}}\right)$ of the frequency estimates, the extreme values $\left(f_{\min }\right.$, $\left.f_{\max }\right)$ of each frequency as well as the mean value $\left(\zeta_{\text {ave }}\right)$ and the standard deviation $\left(\sigma_{\zeta}\right)$ of identified damping. It should be noticed that the lower modes have been automatically identified with high occurrence during the first 6 months, with the identification rate being larger than $98 \%$ for modes $\mathrm{C} 1-\mathrm{C} 5$ and equal to $90.7 \%$ for mode $\mathrm{C} 6$; on the other hand, the identification rate decreases to $77.1 \%$ for modes $\mathrm{C} 7$ and to $36 \%$ for mode $\mathrm{C} 8$.

As shown in Table 1 and Fig. 12, all identified resonant frequencies exhibit slight but clear variations in time: the standard deviation ranges between $0.06 \mathrm{~Hz}$ (mode $\mathrm{C} 1$ ) and $0.34 \mathrm{~Hz}$ (mode C8) and the frequency fluctuations are almost completely driven by the changing temperature, whereas the average relative humidity seems to slightly affects only the frequency of the fundamental mode $(\mathrm{C} 1)$. Especially the frequencies associated to modes with dominant motion in the longitudinal direction of the Cathedral (modes $\mathrm{C} 2$ and C6, Figs. 8c and $8 \mathrm{~g}$ ) reveal clear daily variations (Fig. 12), with the natural frequencies increasing as 
(indoor and outdoor) temperature decreases. This peculiar trend is exemplified in Fig. 13, where the frequency and outdoor temperature variation are zoomed, in a time interval of 10 days, for modes C5 (Fig. 13a) and C6 (Fig. 13b): the peaks in the frequency correspond to the valleys (relative minima) of the outdoor temperature.

Table 1. Statistics of the natural frequencies and damping ratios identified (SSI-Cov) from $16 / 10 / 2018$ to $13 / 04 / 2019$.

\begin{tabular}{cccccccc}
\hline Mode & Id. rate $(\%)$ & $f_{\text {ave }}(\mathrm{Hz})$ & $\sigma_{\mathrm{f}}(\mathrm{Hz})$ & $f_{\min }(\mathrm{Hz})$ & $f_{\max }(\mathrm{Hz})$ & $\zeta_{\text {ave }}(\%)$ & $\sigma_{\zeta}(\%)$ \\
\hline \hline C1 & 99.8 & 1.378 & 0.006 & 1.359 & 1.394 & 3.80 & 0.24 \\
$\mathrm{C} 2$ & 99.8 & 1.687 & 0.018 & 1.630 & 1.739 & 5.60 & 0.64 \\
$\mathrm{C} 3$ & 99.1 & 1.991 & 0.013 & 1.956 & 2.036 & 3.31 & 0.47 \\
$\mathrm{C} 4$ & 98.1 & 2.530 & 0.018 & 2.484 & 2.586 & 3.20 & 0.41 \\
$\mathrm{C} 5$ & 98.2 & 2.666 & 0.015 & 2.617 & 2.711 & 1.27 & 0.30 \\
$\mathrm{C} 6$ & 90.7 & 2.779 & 0.029 & 2.683 & 2.883 & 5.16 & 0.51 \\
$\mathrm{C} 7$ & 77.1 & 3.156 & 0.025 & 3.066 & 3.234 & 2.40 & 0.43 \\
$\mathrm{C} 8$ & 36.0 & 4.185 & 0.033 & 4.107 & 4.307 & 1.79 & 0.30 \\
\hline
\end{tabular}

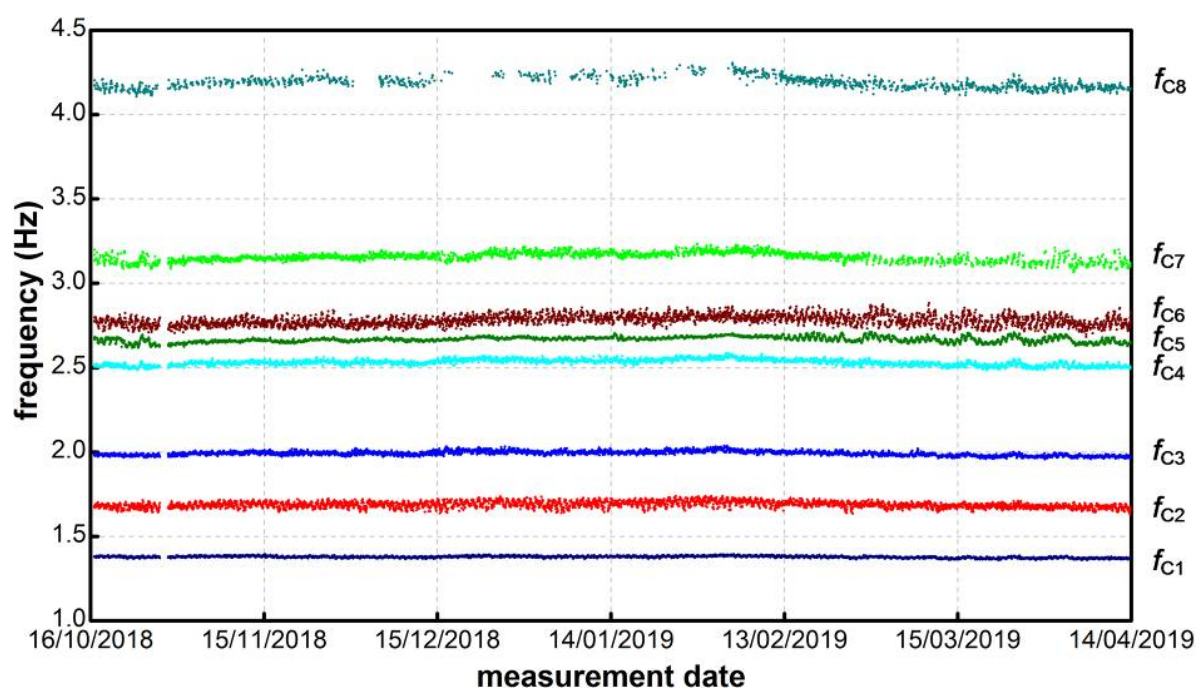

Fig. 12. Automatically identified natural frequencies of the Milan Cathedral versus time (from 16/10/2018 to 13/04/2019).

Unlike strains and rotations, exhibiting a much higher correlation with the indoor temperature, the natural frequencies show similar correlation with both inside and outside temperature. Due to the larger range of variation $\left(-1.65^{\circ} \mathrm{C} \leq T_{\text {outdoor }} \leq+28.2{ }^{\circ} \mathrm{C}\right.$, Fig. $\left.9 \mathrm{~b}\right)$, the outdoor temperature was preferred to exemplify the temperature-frequency correlation. All natural frequencies are plotted versus the outdoor temperature in Fig. 14, along with best fit lines: 
even if for a given temperature a quite remarkable frequency variation is observed, the natural frequencies of the Cathedral almost linearly increase with decreased temperature during the monitoring time span.

(a)

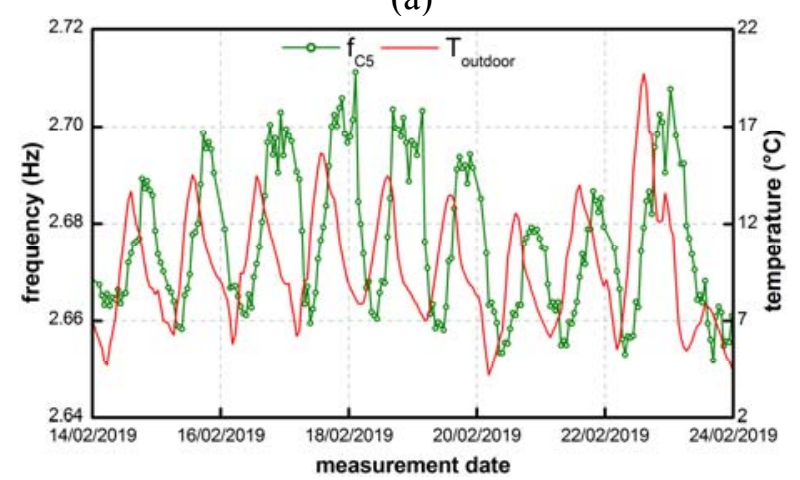

(b)

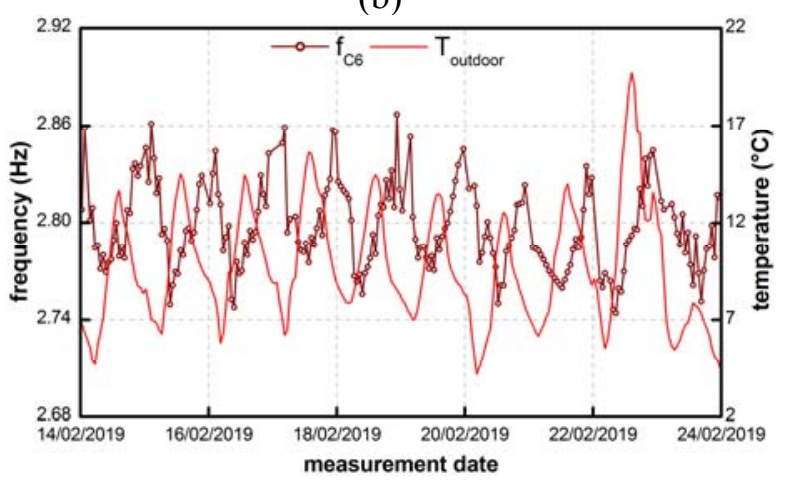

Fig. 13. Zoomed variation of outdoor temperature and identified natural frequency: (a) mode C5; (b) mode C6.
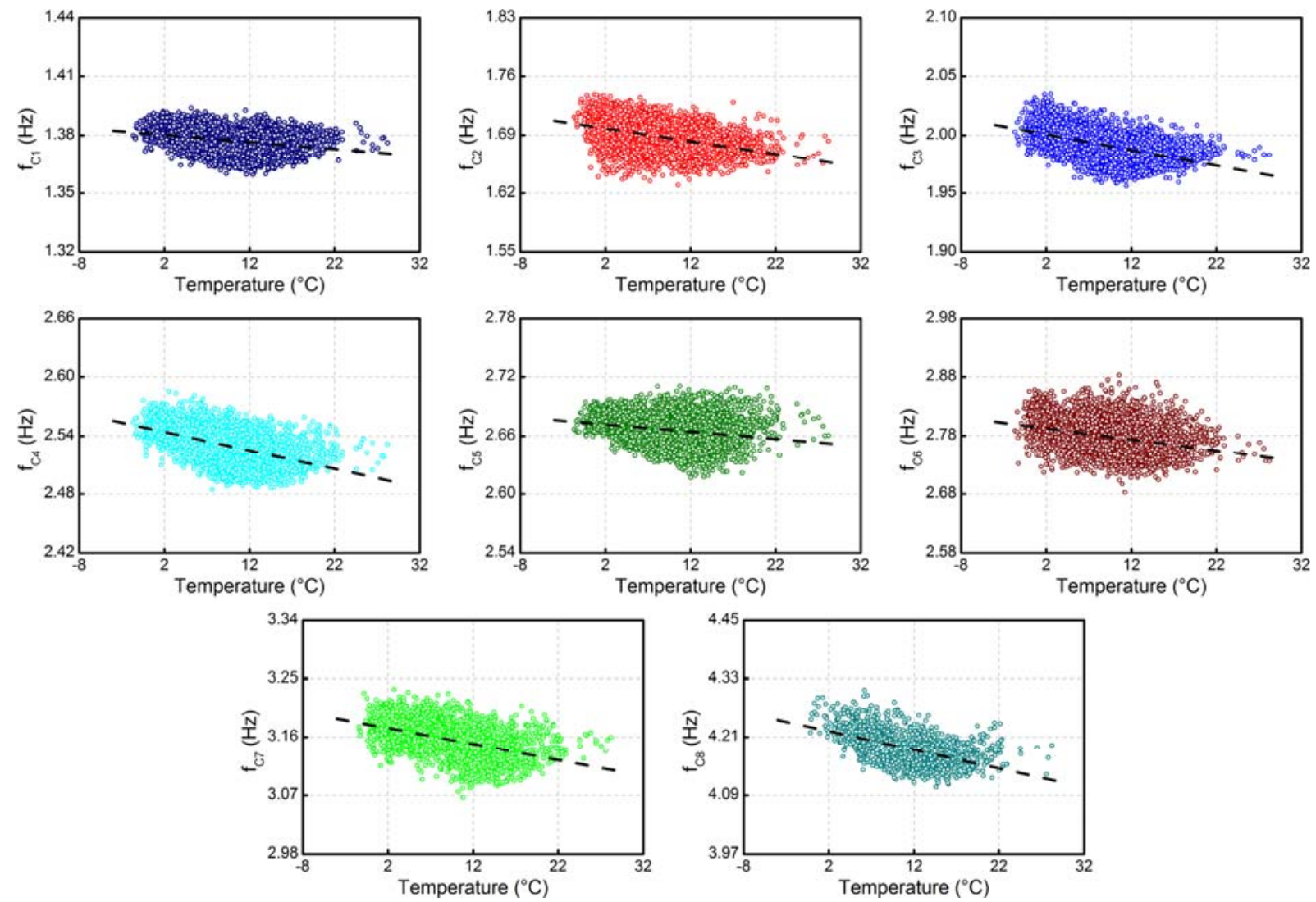

Fig. 14. Correlation between outdoor temperature and identified natural frequencies (from 16/10/2018 to 13/04/2019).

The negative dependence of natural frequencies on temperature is a distinctive behaviour of the Milan Cathedral, with this trend being very different from what reported in almost all the 
long-term studies on masonry structures, either towers [11-12, 16-17, 22] or churches [11, 1315]. In those studies, the increase of natural frequencies with increased temperature is generally documented and explained (see e.g. [12]) as the effect of the closure of cracks, minor masonry discontinuities and mortar gaps induced by the thermal expansion of materials, so that a temporary stiffening of the structure is generated.

In the authors' opinion, the negative frequency-temperature correlation in the Milan Cathedral is determined by the structural arrangement, consisting of double vault system constrained by an extended net of metallic tie-rods (Fig. 3): as a matter of fact, the extensometers installed in the tie-rods highlight a generalized strain increase (Fig. 10a) with decreased temperature, so that the corresponding increased forces in the tension bars conceivably exert a stiffening action on the overall structure. In order to better understand this effect, it should be recalled (Figs. 3 a 4a) that the metallic tie-rods provide a thrust-resisting mechanism but form also a grid of stiffening elements spread over the entire Cathedral. It is further noticed that a similar negative frequency-temperature correlation is only reported in the literature for a monumental building [18], which is characterized by the presence of metallic tie-rods, as well.

As already pointed out in Sections 3 and 4, a relatively large number (27) of seismometers is installed in the Cathedral, so that the investigation of mode shape variations [21] is allowed as well: this analysis is of utmost importance because mode shapes provide both local and global information on the structure. In addition, even for complex systems, the mode shapes are supposed to be less sensitive [21-22] than natural frequencies to environmental changes (which affect almost uniformly the structure) and conceivably more sensitive to local structural changes.

The correlation between outdoor temperature and mode shape variation, in terms of (1-MAC), is shown in Fig. 15. The inspection of Fig. 15 confirms that the MAC values (i.e. the mode shapes) are approximately independent from temperature and time invariant, even if the standard deviation of the MAC tend to increase with the increasing mode order (and the increasing spatial complexity of the mode shape, Fig. 8). Table 2 summarizes the statistical 
characteristics of the MAC in terms of average value $\left(\mathrm{MAC}_{\mathrm{ave}}\right)$, standard deviation $\left(\sigma_{\mathrm{MAC}}\right)$ and minimum value $\left(\mathrm{MAC}_{\min }\right)$; moreover, the coefficient of determination $R^{2}{ }_{\text {MAC-T }}$ is also shown in Fig. 15 (as well as in Table 2) in order to underline that the outdoor temperature practically does not affect the MAC of modes C1-C2 and C4-C6 $\left(R^{2}<0.010\right)$ and has a minor influence on the MAC of the other modes (with $R^{2}$ ranging between 0.066 and 0.202 ).
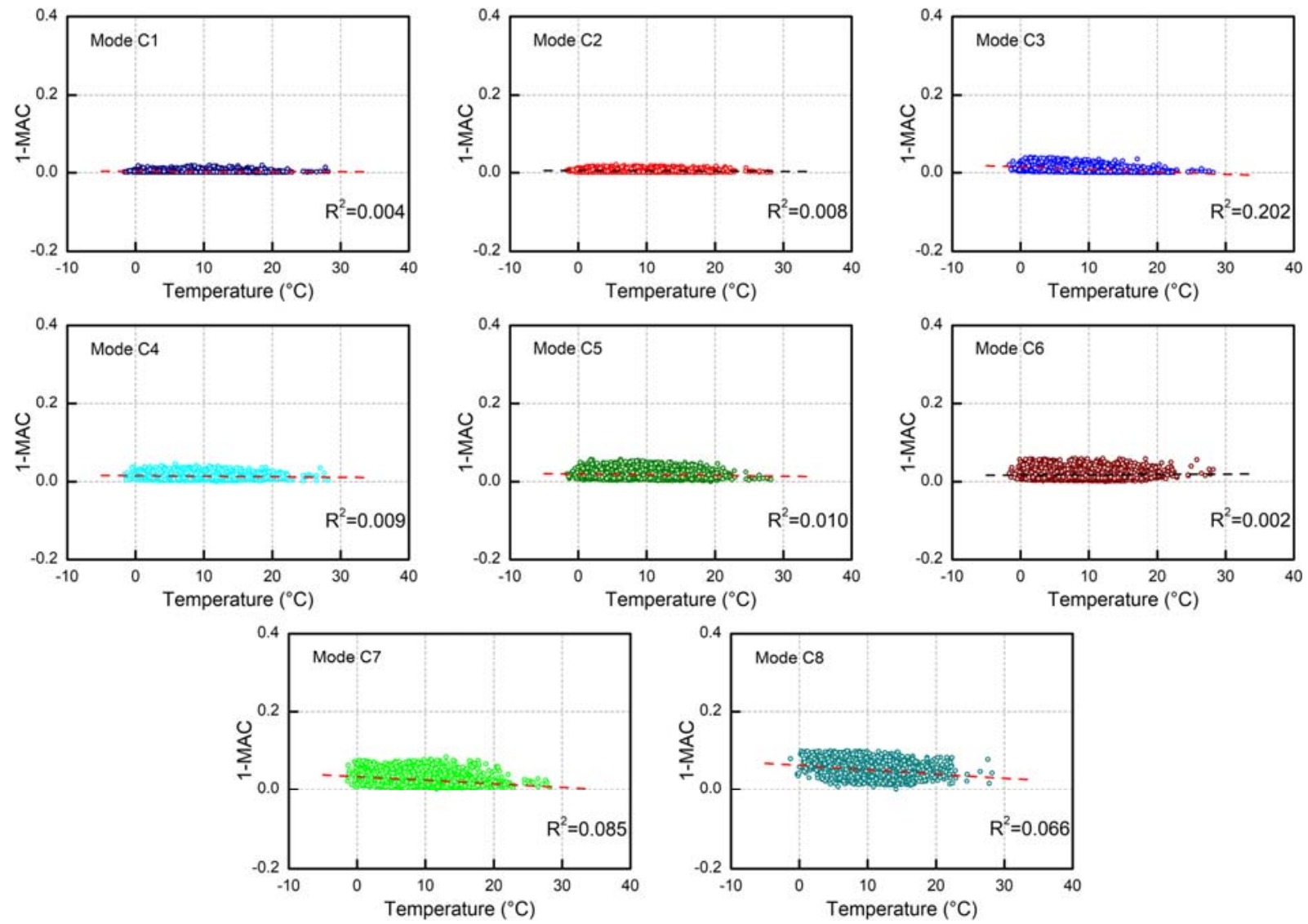

Fig. 15. Correlation between outdoor temperature and (1-MAC) of identified modes (from 16/10/2018 to 13/04/2019).

Table 2. Statistical description of the MAC values from 16/10/2018 to 13/04/2019.

\begin{tabular}{ccccc}
\hline Mode & $\mathrm{MAC}_{\mathrm{ave}}$ & $\sigma_{\mathrm{MAC}}$ & $\mathrm{MAC}_{\min }$ & $\mathrm{R}_{\text {MAC-T }}^{2}$ \\
\hline \hline $\mathrm{C} 1$ & 0.997 & 0.002 & 0.981 & 0.004 \\
$\mathrm{C} 2$ & 0.995 & 0.003 & 0.979 & 0.008 \\
$\mathrm{C} 3$ & 0.991 & 0.007 & 0.960 & 0.202 \\
$\mathrm{C} 4$ & 0.986 & 0.007 & 0.954 & 0.009 \\
$\mathrm{C} 5$ & 0.982 & 0.010 & 0.942 & 0.010 \\
$\mathrm{C} 6$ & 0.982 & 0.011 & 0.940 & 0.002 \\
$\mathrm{C} 7$ & 0.974 & 0.016 & 0.915 & 0.085 \\
$\mathrm{C} 8$ & 0.949 & 0.020 & 0.901 & 0.066 \\
\hline
\end{tabular}



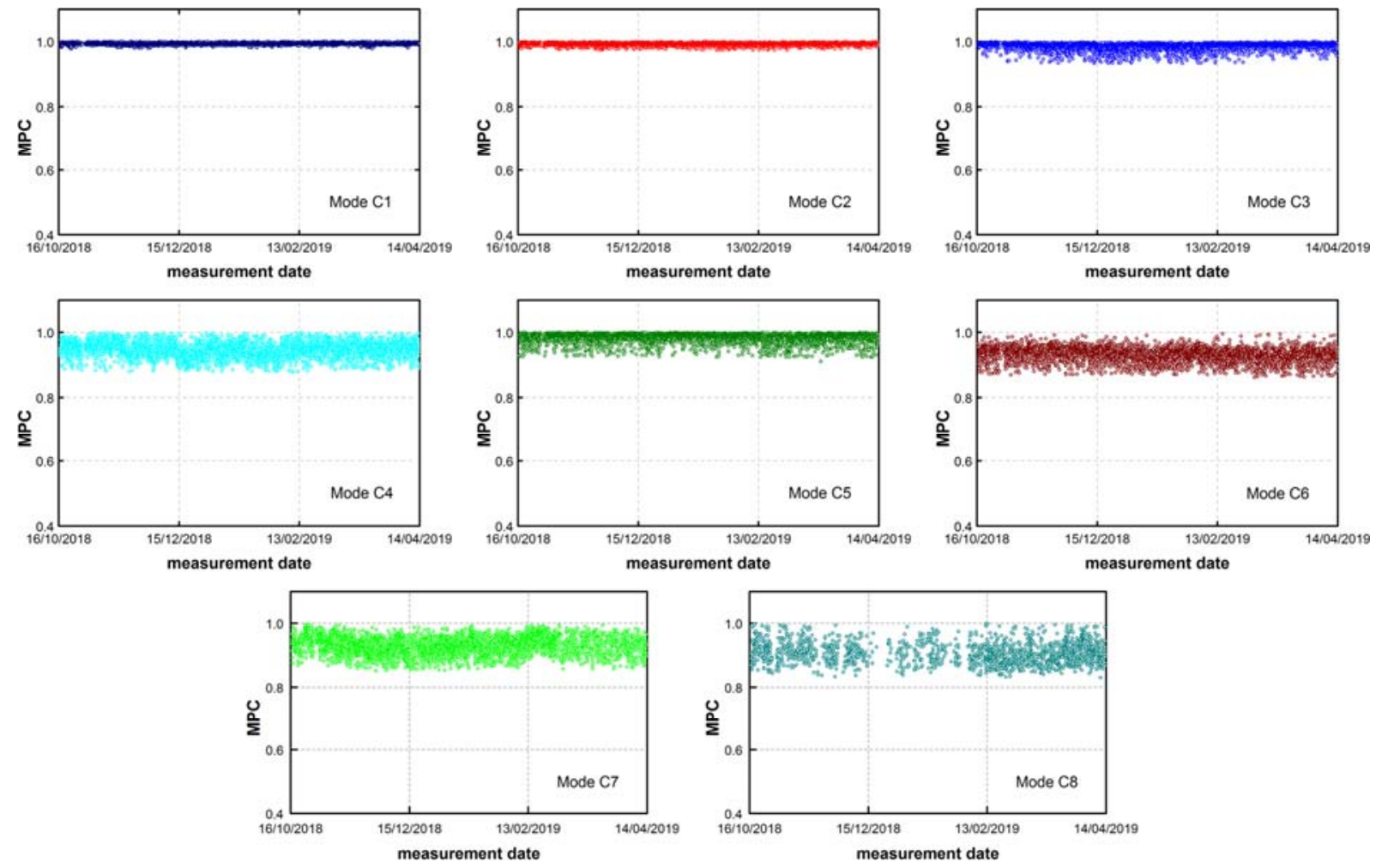

Fig. 16. Variation in time of the MPC of identified modes from 16/10/2018 to 13/04/2019.

Finally, Fig. 16 and Table 3 demonstrates that also the MPC measure of mode complexity [25] is approximately time invariant, even if the MPC values (Fig. 16) tend to depart from unity and to exhibit an increased dispersion for the higher modes.

Table 3. Statistical description of the MPC values from 16/10/2018 to 13/04/2019.

\begin{tabular}{cccccc}
\hline Mode & $\mathrm{MPC}_{\mathrm{ave}}$ & $\sigma_{\mathrm{MPC}}$ & $\mathrm{MPC}_{\min }$ & $\mathrm{MPC}_{\max }$ & $\mathrm{R}_{\text {MPC-T }}^{2}$ \\
\hline \hline $\mathrm{C} 1$ & 0.993 & 0.003 & 0.978 & 1.000 & 0.002 \\
$\mathrm{C} 2$ & 0.992 & 0.004 & 0.973 & 1.000 & 0.004 \\
$\mathrm{C} 3$ & 0.985 & 0.012 & 0.932 & 1.000 & 0.097 \\
$\mathrm{C} 4$ & 0.946 & 0.024 & 0.880 & 1.000 & 0.042 \\
$\mathrm{C} 5$ & 0.983 & 0.015 & 0.910 & 1.000 & 0.001 \\
$\mathrm{C} 6$ & 0.930 & 0.022 & 0.862 & 0.996 & 0.001 \\
$\mathrm{C} 7$ & 0.930 & 0.028 & 0.852 & 0.996 & 0.004 \\
$\mathrm{C} 8$ & 0.907 & 0.034 & 0.830 & 0.999 & 0.011 \\
\hline
\end{tabular}

\section{CONCLUSIONS AND FUTURE DEVELOPMENTS}

The paper focuses on the description of the monitoring system recently designed and installed in the Milan Cathedral. The monitoring system, aimed at enhancing the knowledge and 
assisting the condition-based structural maintenance of the historic building, includes more than 120 sensors belonging to different classes (i.e., a network of 12 extensometers, 15 biaxial tilt-meters, 36 seismometers, 30 temperature sensors, 12 hygrometers and 1 weather station) and is fully computer based and characterized by distributed architecture.

Special emphasis is given on the dynamic measurements, the automated extraction of modal signatures and the influence of environmental parameters on the variations observed in the quasi-static measurements and in the dynamic characteristics of the Cathedral. Based on the results obtained in the first 6 months of continuous monitoring (i.e., between 16/10/2018 and 13/04/2019), the following main conclusions can be drawn:

1. The application of state-of-art tools for automated operational modal analysis allows estimate and tracking of eight resonant frequencies in the frequency interval 0-5 Hz. The automatically identified frequencies involve dominant motion in the main transverse $(\mathrm{N}-$ S) and longitudinal (E-W) direction of the Cathedral;

2. The (outdoor and indoor) temperature turned out to be a dominant driver of the variations observed in the quasi-static measurements (strain of the tie-rods and tilt of the piers) and of daily fluctuation of the resonant frequencies of all modes. The relative humidity seems to slightly affects only the frequency of the first mode;

3. Even if the observation period is relatively limited, the frequency-temperature correlations reveal a distinctive trend, which is very different from what reported in almost all the long-term studies on historic masonry structures. All resonant frequencies of the Milan Cathedral almost linearly increase with decreased temperature, and the negative dependence of modal frequencies on temperature is conceivably determined by the action exerted by the metallic tie-rods in the structural arrangement of the monumental building;

4. The mode shapes of the Cathedral and the corresponding mode complexity do not exhibit appreciable fluctuations associated to the environmental effects, so that an appropriate strategy of SHM should be based [21] on the time invariance of those parameters. On the other hand, localizing an anomalous structural change from modal deflections is a 
challenging task as mode shapes might be not enough sensitive to the onset of local damage.

As a final remark on the lessons learned from the first months of continuous monitoring, it should be stated that the future vibration-based SHM of the monument will involve: (a) the use of both supervised (such as multiple linear regression [33]) and unsupervised (principal component analysis [34] or second order blind identification [35]) algorithms to remove/mitigate the masking effects induced by the temperature changes on the identified resonant frequencies and (b) the check of the invariance of mode shapes and mode complexity [21]. In addition, the availability of several quasi-static measurements should conceivably be exploited in a data fusion framework for an enhanced program of condition-based structural maintenance.

\section{ACKNOWLEDGEMENTS}

The support of Veneranda Fabbrica del Duomo di Milano is gratefully acknowledged. The authors would like to thank the technical staff of AGISCO and Veneranda Fabbrica del Duomo di Milano for the installation of all monitoring devices, and the technical staff of SARA Electronics Instruments for the assistance during the mounting and the initial operational setting of the seismometers.

\section{REFERENCES}

[1] C. Ferrari da Passano, Storia della Veneranda Fabbrica del Duomo (in Italian), Cassa di Risparmio delle Province Lombarde, Milan, 1973.

[2] Annali della Fabbrica del Duomo di Milano. Dall'origine fino al presente, Veneranda Fabbrica del Duomo, Milan, 1885.

[3] A. Nava, Relazione dei ristauri intrapresi alla Gran Guglia del Duomo di Milano (in Italian), Tipografia Valentini \& C, Milan, 1848.

[4] A. Zacchi, Private comnunication (in Italian), Archives of Veneranda Fabbrica del Duomo, Milan, 1941.

[5] A. Cigada, L. Corradi Dell'Acqua, B. Mörlin Visconti Castiglione, M. Scaccabarozzi, M. Vanali, E. Zappa, Structural health monitoring of an historical building: The main spire of the Duomo di Milano, Int. J. Archit. Herit. 11(4) (2016) 501-518. https://doi.org/10.1080/15583058.2016.1263691

[6] C. Ferrari da Passano, Il Duomo rinato (in Italian), Veneranda Fabbrica del Duomo (Diakronia), Milan, 1988. 
[7] G. Vicentini, Il pendolo registratore dei movimenti dell'aguglia maggiore del Duomo di Milano (in Italian), Hoepli, Milan, 1906.

[8] C. Gentile, C. Poggi, A. Ruccolo, M. Vasic, Vibration-based assessment of the tensile force in the tie-rods of the Milan Cathedral, Int. J. Archit. Herit. 13(3) (2019) 411-424. https://doi.org/10.1080/15583058.2018.1563235

[9] C. Gentile, F. Canali, Continuous Monitoring the Cathedral of Milan: design, installation and preliminary results. In: Proceedings 2018, 2(8), 467.

https://doi.org/10.3390/ICEM18-05354

[10] H. Sohn, Effects of environmental and operational variability on structural health monitoring, Philos. Trans. R. Soc. A 365 (2007) 539-560.

https://doi.org/10.1098/rsta.2006.1935

[11] L.F. Ramos, L. Marques, P.B. Lourenço, G. De Roeck, A. Campos-Costa, J. Roque, Monitoring historical masonry structures with operational modal analysis: two case studies, Mech. Syst. Signal Pr. 24(5) (2010) 1291-1305.

https://doi.org/10.1016/j.ymssp.2010.01.011

[12] A. Saisi, C. Gentile, M. Guidobaldi, Post-earthquake continuous dynamic monitoring of the Gabbia Tower in Mantua, Italy, Constr. Build. Mater. 81 (2015) 101-112. https://dx.doi.org/10.1016/j.conbuildmat.2015.02.010

[13] M.G. Masciotta, J.C.A. Roque, L.F. Ramos, P.B. Lourenço, A multidisciplinary approach to assess the health state of heritage structures: The case study of the Church of Monastery of Jerónimos in Lisbon, Constr. Build. Mater. 116 (2016) 169-187. https://dx.doi.org/10.1016/j.conbuildmat.2016.04.146

[14] M.G. Masciotta, L.F. Ramos, P.B. Lourenço, The importance of structural monitoring as a diagnosis and control tool in the restoration process of heritage structures: A case study in Portugal, J. Cult. Heritage 27 (2017) 36-47.

https://dx.doi.org/10.1016/j.culher.2017.04.003

[15] A. Elyamani, O. Caselles, P. Roca, J. Clapes, Dynamic investigation of a large historical cathedral, Struct. Control Health Monit. 24(3) (2017) e1885. https://doi.org/10.1002/stc. 1885

[16] F. Ubertini, N. Cavalagli, A. Kita, G. Comanducci, Assessment of a monumental masonry bell-tower after 2016 Central Italy seismic sequence by long-term SHM, Bull. Earthquake Eng. 16(2) (2018) 775-801. https://doi.org/10.1007/s10518-017-0222-7

[17] A. Saisi, C. Gentile, A. Ruccolo, Continuous monitoring of a challenging heritage tower in Monza, Italy, Journal of Civil Structural Health Monitoring 8 (2018) 77-90. https://doi.org/10.1007/s13349-017-0260-5

[18] A. Kita, N. Cavalagli, F. Ubertini, Temperature effects on static and dynamic behavior of Consoli Palace in Gubbio, Italy, Mech. Syst. Signal Pr. 120 (2019) 180-202 https://doi.org/10.1016/j.ymssp.2018.10.021

[19] N. Aste, R.S. Adhikari, M. Buzzetti, S. Della Torre, C. Del Pero, H.E. Huerto C.F. Leonforte, Microclimatic monitoring of the Duomo (Milan Cathedral): Risks-based analysis for the conservation of its cultural heritage, Build. Environ. 148 (2019) 240257. https://doi.org/10.1016/j.buildenv.2018.11.015

[20] W. Fan, P. Qiao, Vibration-based damage identification methods: a review and comparative study. Struct. Health Monit., 10(1) (2011) 83-111. 
https://doi.org/10.1177/1475921710365419

[21] A. Cabboi, C. Gentile, A. Saisi, Vibration-based SHM of a centenary bridge: a comparative study between two different automated OMA techniques. In: Proceedings of the 9th international conference on structural dynamics (EURODYN 2014), European Association for Structural Dynamics, 2014, pp. 1461-1468.

[22] R.M. Azzara, G. De Roeck, M. Girardi, C. Padovani, D. Pellegrini, E. Reynders, The influence of environmental parameters on the dynamic behaviour of the San Frediano bell tower in Lucca, Eng. Struct. 156 (2018) 175-187.

https://doi.org/10.1016/j.engstruct.2017.10.045

[23] https://www.agisco.it/en/, website of AGISCO (Advances Geothecnical Intrumentation Systems and Consulting). Accessed 12 May 2019

[24] https://www.sara.pg.it/?lang=en, website of SARA Electronics Instruments. Accessed 12 May 2019

[25] R.S. Pappa, K.B. Elliott, A. Schenk, A consistent-mode indicator for the eigensystem realization algorithm, NASA Technical Memorandum 107607, NASA Langley Research Center, Hampton, 1992.

[26] W. Heylen, S. Lammens, P. Sas, Modal Analysis: Theory and Testing, KU Leuven, Belgium, 2007.

[27] E. Reynders, J. Houbrechts, G. De Roeck, Fully automated (operational) modal analysis, Mech. Syst. Signal Pr. 29 (2012) 228-250.

https://doi.org/10.1016/j.ymssp.2012.01.007

[28] G.C. Sebregondi, R. Schoefield, First Principles: Gabriele Stornaloco and Milan Cathedral, Architectural History 59 (2016) 63-122. https://doi.org/10.1017/arh.2016.3

[29] B. Peeters, G. De Roeck, Reference-based stochastic subspace identification for outputonly modal analysis, Mech. Syst. Signal Pr. 13(6) (1999) 855-878.

https://doi.org/10.1006/mssp.1999.1249

[30] A. Cabboi, F. Magalhães, C.Gentile, À. Cunha, Automated modal identification and tracking: application to an iron arch bridge, Struct. Control Health Monit. 24(1) (2017) e1854. doi: $10.1002 /$ stc. 1854

[31] R.J. Allemang, D.L. Brown, A correlation coefficient for modal vector analysis. In: Proceedings of the $1^{\text {st }}$ International Modal Analysis Conference (IMAC-I), 1982, pp. 110-116.

[32] R. Brincker, L. Zhang, P. Andersen, Modal identification of output-only systems using frequency domain decomposition, Smart Mater. Struct. 10 (2001) 441-445. doi: $10.1088 / 0964-1726 / 10 / 3 / 303$

[33] R.L. Mason, R.F. Gunst, J.L. Hess, Statistical design and analysis of experiments with applications to engineering and science, John Wiley \& Sons, New York, 2003.

[34] I.T. Jolliffe, Principal component analysis, Springer, New York, 2002.

[35] C. Rainieri, F. Magalhães, D. Gargaro, G. Fabbrocino, À. Cunha, Predicting the variability of natural frequencies and its causes by Second Order Blind Identification, Struct. Health Monit. 18(2) (2019) 486-507. https://doi.org/10.1177/1475921718758629 